\title{
Dynamic Stability of Maglev Systems
}

by

Y. Cai, S. S. Chen, and T. M. Mulcahy

Materials and Components Technology Division

D. M. Rote

Center for Transportation Research

April 1992

Work supported b?

U.S. DEPAR'TMENT OF ENERGY

Office of Transportation Technologies 


\section{Contents}

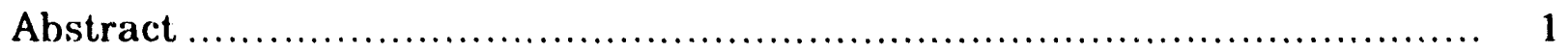

1 Introduction .......................................................................... 1

1.1 Theoretical Studies ................................................................ 2

1.2 Experimental Studies....................................................... 2

1.3 Experimental/Analytical Studies........................................ 2

2 Motion-Dependent Magnetic Forces..................................................... 3

2.1 Motion-Dependent Magnetic-Force Coefficients............................... 3

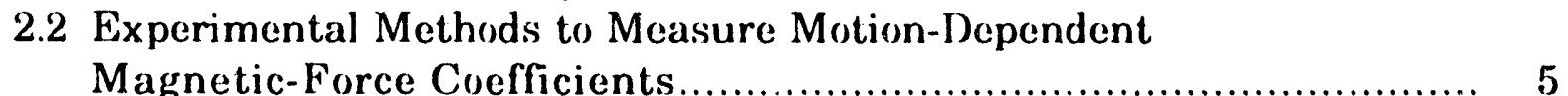

2.3 Quasistatic Motion-Dependent Magnetic-Force Coefficients of Maglev System with L-Shaped Guideway .............................. 6

3 Stability of Maglev Systems .................................................... 12

4 Simplified Vehicle Models for Dynamic Instability ........................... 18

4.1 Two-Degree-of-Freedom Vehicle............................................ 19

4.2 Three-Degree-of-Freedom Vehicle ......................................... 22

4.3 Six-Degree-of-Freedom Vehicle ............................................ 266

4.4 Vehicle on Double L-Shaped Aluminum Sheet Guideway ................. 26

5 Closing Remarks ............................................................... 36

Acknowledgments.................................................................... 39

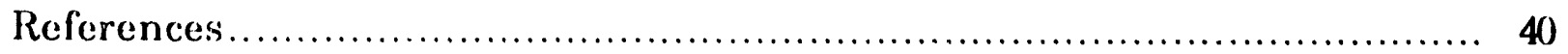




\section{Figures}

1 Displacement components of a maglev system .......................... 4

2 Experimental apparatus for magnetic force measurement............... 7

3 Schematic diagram of the apparatus used to measure magnetic forces on an L-shaped aluminum sheet guideway ....................... $\quad 7$

4 Measured lift and guidance magnetic forces............................. 8

$5 \quad$ Measured lift and guidance magnetic stiffness ........................ 13

6 Magnetic forces divided by image force...................................... 20

$7 \quad$ Natural frequency as a function of levitation height................... 22

8 Three-degree-of-freedom vehicle...................................... 23

9 Maglev system with a vehicle operating on double L-shaped aluminum sheet guideway .......................................... 27

10 Displacement components of three-degree-of-freedom vehicle.......... 29

11 Maglev-system eigenvalues vs. vehicle levitation height, with $\mathrm{Y}^{*}=12.7 \mathrm{~mm}$.

12 Modal shapes of three-degree-of-freedom maglev system with $\mathrm{Y}^{*}=12.7 \mathrm{~mm}$.

13 Maglev-system eigenvalues vs. vehicle levitation height, with $\mathrm{Y}^{*}=5 \mathrm{~mm}$

14 Maglev-system eigenvalues vs. lateral location of vehicle, with $\mathrm{h}=12.7 \mathrm{~mm}$ and $\mathrm{g}_{0}=25 \mathrm{~mm}$

15 Maglev-system eigenvalues vs. lateral location of vehicle, with $\mathrm{h}=7 \mathrm{~mm}$ and $\mathrm{g}_{0}=25 \mathrm{~mm}$

16 Real part of maglev-system eigenvalues vs. lateral location of vehicle, with $\mathrm{h}=7 \mathrm{~mm}$ and $\mathrm{g}_{0}=10,15,20$, and $25 \mathrm{~mm}$ 


\section{Table}

1 Eigenvectors of vehicle motion.............................................. 32 


\title{
Dynamic Stability of Maglev Systems
}

\author{
by \\ Y. Cai, S. S. Chen, T. M. Mulcahy, and D. M. Rote
}

\section{Abstract}

Because dynamic instability is not acceptable for any commercial maglev systems, it is important to consider this phenomenon in the development of all maglev systems. This study considers the stability of maglev systems based on experimental data, scoping calculations, and simple mathematical models. Divergence and flutter are obtained for coupled vibration of a three-degree-offreedom maglev vehicle on a guideway consisting of double L-shaped aluminum segments attached to a rotating wheel. The theory and analysis developed in this study identifies basic stability characteristics and future research needs of maglev systems.

\section{Introduction}

The dynamic response of maglev systems is important in several respects: safety and ride quality, guideway design, and system costs. Ride quality is determined by vehicle response and by environmental factors such as humidity and noise. The dynamic response of vehicles is the key element in the determination of ride quality, and vehicle stability is one of the important elements relative to safety. To design a proper guideway that provides acceptable ride quality in the stable region, the vehicle dynamics must be understood. Furthermore, the trade-off between guideway smoothness and the levitation and control systems must be considered if maglev systems are to be economically feasible. The link between the guideway and other maglev components is vehicle dynamics. For a commercial maglev system, vehicle dynamics must be analyzed and tested in detail.

For safety, maglev systems should be stable. Magnetic forces are basically position-dependent, although some are also velocity-dependent. These motiondependent magnetic forces can induce various types of instability. In addition, the periodic structure of the motion-dependent magnetic forces may in some cases also induce parametric and combination resonances. 
Some analytical and experimental studies have been performed to understand the stability characteristics of maglev systems. Several examples are summarized briefly as follows:

\subsection{Theoretical Studies}

- Davis and Wilkie (1971) studied a magnetic coil moving over a conducting track and concluded that negative damping occurs at velocities greater than the characteristic velocity based on thin-track theory.

- Ohno et al. (1973) studied the pulsating lift forces in a linear synchronous motor. These forces may cause parametric and combination resonances, as well as heave and pitch oscillations.

- Baiko et al. (cited in Chu and Moon 1983) considered the interactions of induced eddy currents with on-board superconducting magnets and found possible heave instabilities.

\subsection{Experimental Studies}

- An experimental vehicle floating above a large rotating wheel was found by Moon (1974) to have sway-yaw instabilities.

- Experiments performed at MIT on a test track showed pitch-heave instability (Moon 1975).

\subsection{Experimental/Analytical Studies}

- A conducting guideway, consisting of L-shaped aluminum segments attached to a rotating wheel to simulate the Japanese full-scale guideway at Miyazaki, was studied experimentally and analytically by Chu and Moon (1983). Divergence and flutter were obtained for coupled yaw-lateral vibration; the divergence leads to two stable equilibrium yaw positions, and the flutter instability leads to a limit cycle of coupled yaw and lateral motions in the neighborhood of the drag peak.

- Variation of the magnetic lift force due to variation of the levitated height corresponding to the sinusoidal guideway roughness was studied by Yabuno et al. (1989). Parametric resonance of heaving and pitching motions is possible. 
Based on these published analytical results and experimental data, it is obvious that different types of dynamic instabilities can occur in maglev systems. Because dynamic instability is not acceptable for any commercial maglev systems, it is important to consider this phenomenon in the development of all maglev systems.

This study considers the stability of maglev systems and is based on experimental data, scoping calculations, and simple mathematical models. The objective is to provide some basic stability characteristics and to identify future research needs.

\section{Motion-Dependent Magnetic Forces}

\subsection{Motion-Dependent Magnetic-Force Coefficients}

Magnetic forces are needed for any vehicle dynamics analysis, guideway structural design, fastening design, and prediction of ride quality. These force components are considered from the standpoint of vehicle stability.

As an example, consider a vehicle with six degrees of freedom, three translations, $u_{x}, u_{y}, u_{z}$, and three rotations, $\omega_{x}, \omega_{y}, \omega_{z}$, as shown in Fig. 1. Let $U$ be the vector consisting of the six motion components, i.e.,

$$
\mathrm{U}=\left\{\begin{array}{l}
\mathrm{u}_{1} \\
\mathrm{u}_{2} \\
\mathrm{u}_{3} \\
\mathrm{u}_{4} \\
\mathrm{u}_{5} \\
\mathrm{u}_{6}
\end{array}\right\}=\left\{\begin{array}{l}
\mathrm{u}_{\mathrm{x}} \\
\mathrm{u}_{\mathrm{y}} \\
\mathrm{u}_{\mathrm{z}} \\
\omega_{\mathrm{x}} \\
\omega_{\mathrm{y}} \\
\omega_{\mathrm{z}}
\end{array}\right\}
$$

Velocity and acceleration are given by

$$
\dot{U}=\frac{\partial U}{\partial t},
$$

and

$$
\ddot{U}=\frac{\partial^{2} \mathrm{U}}{\partial \mathrm{t}^{2}} .
$$

The motion-dependent magnetic forces can be written 

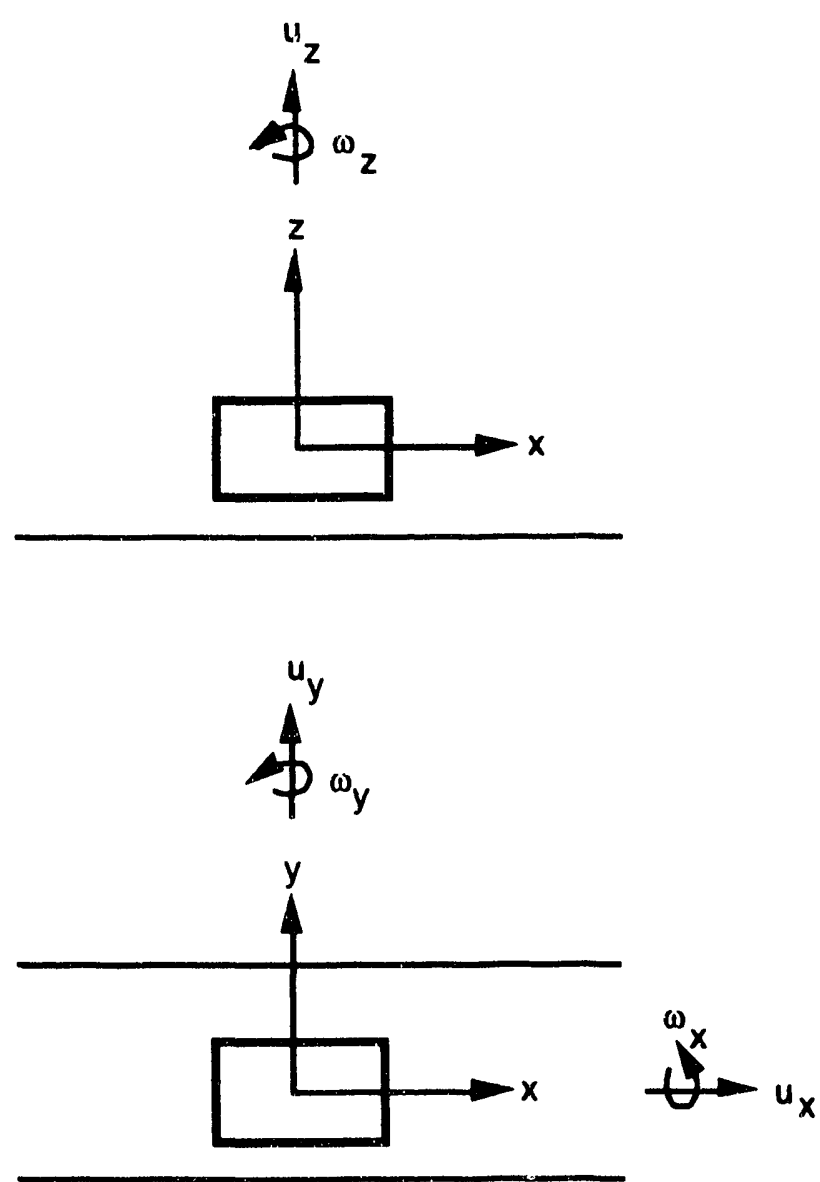

Fig. 1. Displacement components of a maglev system

$$
f_{i}=\sum_{j=1}^{6}\left(m_{i j} \ddot{u}_{j}+c_{i j} \dot{u}_{j}+k_{i j} u_{j}\right),
$$

where $m_{i j}, c_{i j}$, and $k_{i j}$ are magnetic mass, damping, and stiffness coefficients. These coefficients can be obtained analytically, numerically, or experimentally and are functions of the system parameters.

- Analytical Studies: Analyses for simple cases can be performed to determine the characteristics of the coefficients. For example, an analytical method may be used to identify the coefficients that can be neglected under specific conditions.

- Numerical Methods: For the general case with complicated geometries, analytical methods may not be appropriate and numerical methods will be more useful. Numerical methods (finite- 
element method and boundary-element method) can be used to calculate the values of all coefficients under specific conditions.

- Experimental Techniques: Measurements of magnetic forces will give the information required to calculate magnetic-force coefficients.

\subsection{Experimental Methods to Measure Motion-Dependent Magnetic-Force Coefficients}

Quasistatic Motion Theory. The magnetic forces acting on an oscillating vehicle are equal, at any instant in time, to those of the same vehicle moving with a constant velocity and with specific clearances equal to the actual instantaneous values. The magnetic forces depend on the deviation from a reference state of speed and clearance, i.e., the motion-dependent magnetic forces depend only on $u_{j}$, but not $\dot{u}_{j}$ and $\ddot{u}_{j}$, so that

$$
f_{i}=\sum_{j=1}^{6} k_{i j} u_{j}
$$

In this case, the magnetic forces are determined uniquely by vehicie position. All elements of magnetic stiffness $k_{i j}$ can be obtained. To determine $k_{i j}$, the magnetic-force component $f_{i}$ is measured as a function of $u_{j}$. Stiffness is given by

$$
\mathbf{k}_{\mathrm{ij}}=\frac{\partial \mathbf{f}_{\mathrm{i}}}{\partial \mathbf{u}_{\mathrm{j}}}
$$

In general, $k_{i j}$ is a function of $U$.

Unsteady-Motion Theory. The magnetic forces acting on an oscillating vehicle will depend on $U, \dot{U}$, and $\ddot{U}$. The magnetic force based on the unsteadymotion theory can be obtained by measuring the magnetic force acting on the vehicle oscillating in the magnetic field. For example, if the displacement component $u_{j}$ is excited, its displacement is given by

$$
u_{j}=\bar{u}_{j} \exp (\sqrt{-1} \omega t)
$$

The motion-dependent magnetic force of the component $f_{i}$ acting on the vehicle is given by 


$$
f_{i}=\left[a_{i j} \cos \left(\psi_{i j}\right)+\sqrt{-1} a_{i j} \sin \left(\psi_{i j}\right)\right] \bar{u}_{j} \exp (\sqrt{-1} \omega t)
$$

where $a_{i j}$ is the magnetic force amplitude and $\psi_{i j}$ is the phase angle between the magnetic force and the vehicle displacement $u_{j}$. These values are measured experimentally.

Using Eqs. 3 and 6, we can also write the motion-dependent magnetic force component as

$$
f_{i}=\left(-m_{i j} \omega^{2}+\sqrt{-1} \omega c_{i j}+k_{i j}\right) \bar{u}_{j} \exp (\sqrt{-1} \omega t) .
$$

A comparison of Eqs. 7 and 8 yields

$$
\begin{aligned}
& c_{i j}=a_{i j} \sin \left(\psi_{i j}\right) / \omega, \\
& m_{i j}=\left[k_{i j}-a_{i j} \cos \left(\psi_{i j}\right)\right] / \omega^{2} .
\end{aligned}
$$

Based on Eqs. 5 and 9, all motion-dependent magnetic-force matrices can be determined from two experiments: quasistatic motion and unsteady motion.

If $\mathrm{m}_{\mathrm{ij}}$ and $\mathrm{c}_{\mathrm{ij}}$ are of no concern, the experiment using quasisteady motion is sufficient to determine $\mathbf{k}_{\mathrm{ij}}$.

\subsection{Quasistatic Motion-Dependent Magnetic-Force Coefficients of Maglev System with L-Shaped Guideway}

An experiment was conducted recently at Argonne National Laboratory to investigate the lift, drag, and guidance magnetic forces on an $\mathrm{NdFeB}$ permanent magnet moving over an aluminum (6061-T6) L-shaped ring mounted on the top surface of a 1.2-m diameter rotating wheel (shown in Fig. 2). For a given rotating speed of the wheel, the lift and guidance magnetic forces were measured as the guidance gap $\mathrm{Y}^{*}$ and lift height $\mathrm{h}$ were varied. A schematic diagram of the measurement approach is shown in Fig. 3. Figure 4 shows those measured forces as a function of $\mathrm{h}$, with $\mathrm{Y}^{*}$ fixed $\left(\mathrm{Y}^{*}=5 \mathrm{~mm}\right.$ and $\left.12.7 \mathrm{~mm}\right)$, or as a function of $\mathrm{Y}^{*}$ with $\mathrm{h}$ fixed $(\mathrm{h}=7 \mathrm{~mm}$ and $12.7 \mathrm{~mm}$ ) when the surface velocity of the lateral leg of the guideway is $36.1 \mathrm{~m} / \mathrm{s}$, the highest velocity tested.

During testing, the long side of the $25.4 \times 50.8 \times 6.35 \mathrm{~mm}$ rectangular magnet was oriented parallel to the direction of motion of the L-shaped guideway and was 


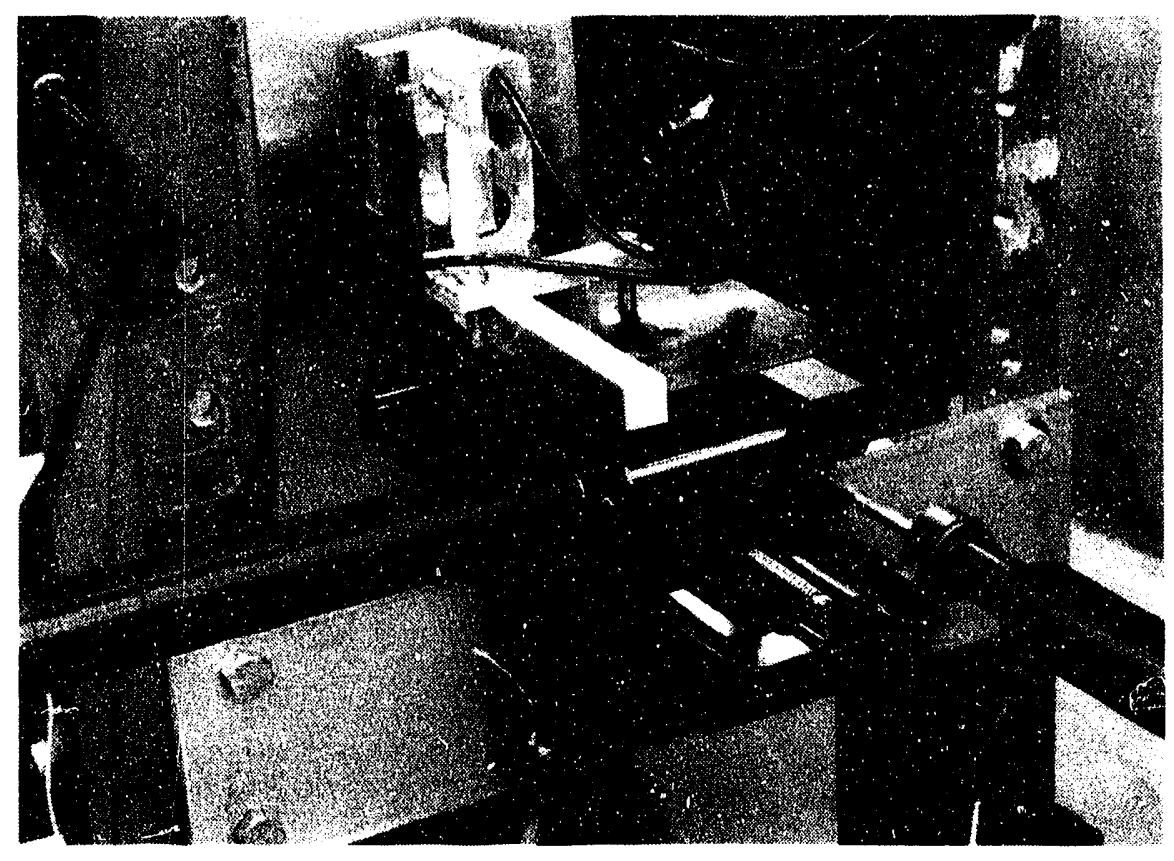

Fig. 2. Experimental apparatus for magnetic force measurement

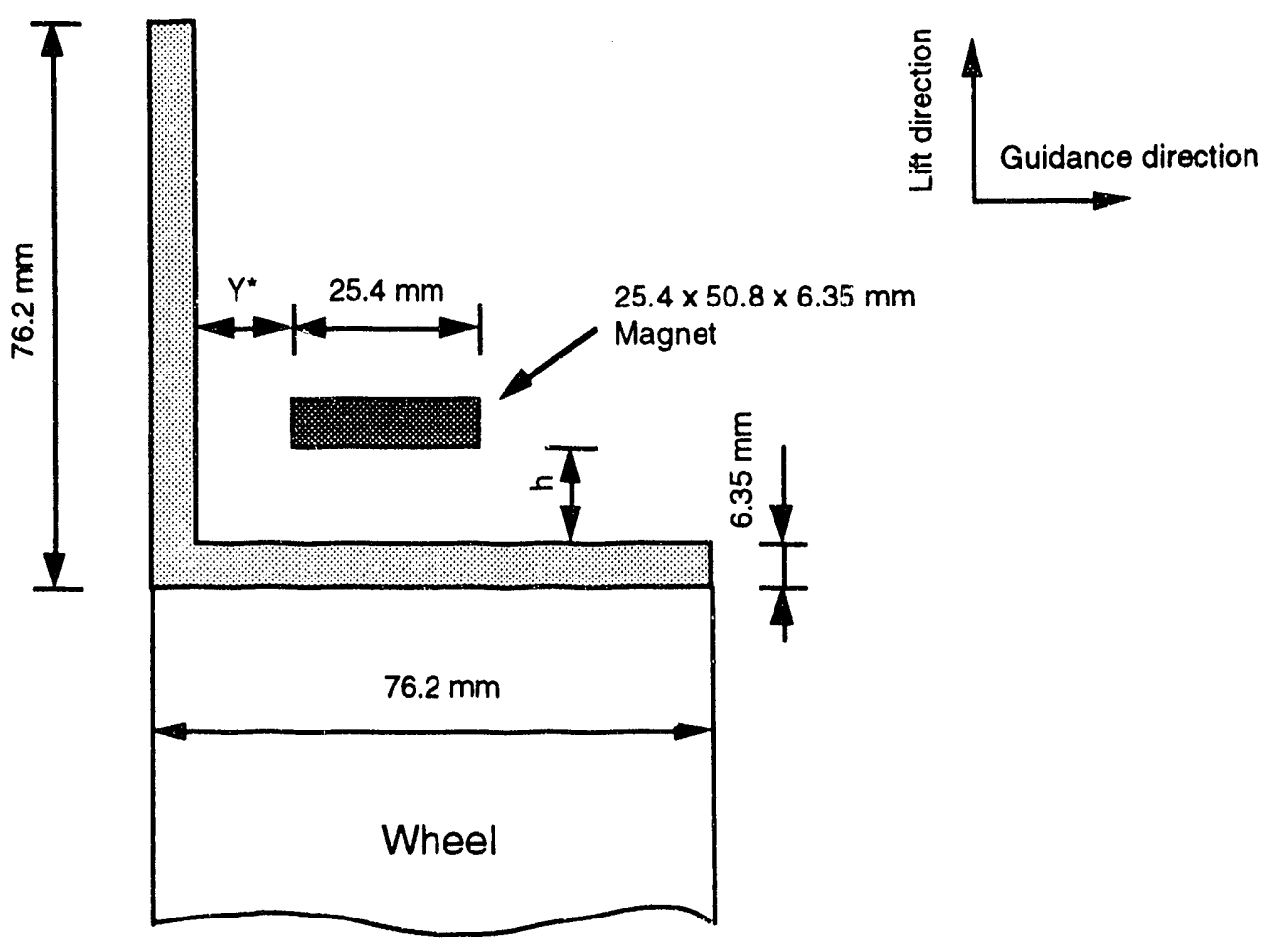

Fig. 3. Schematic diagram of the apparatus used to measure magnetic forces on an L-shaped aluminum sheet ¿uideway 


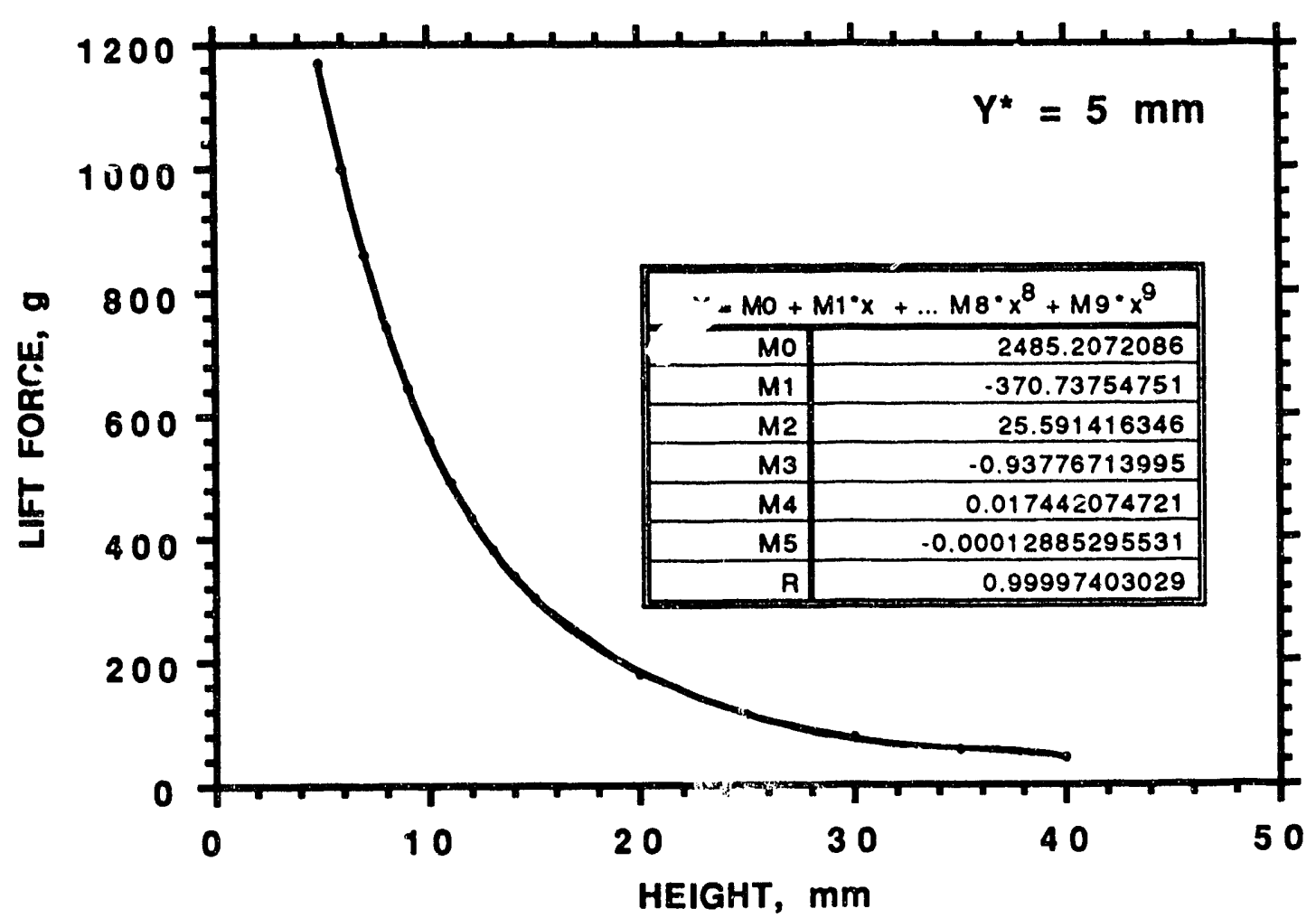

(a)

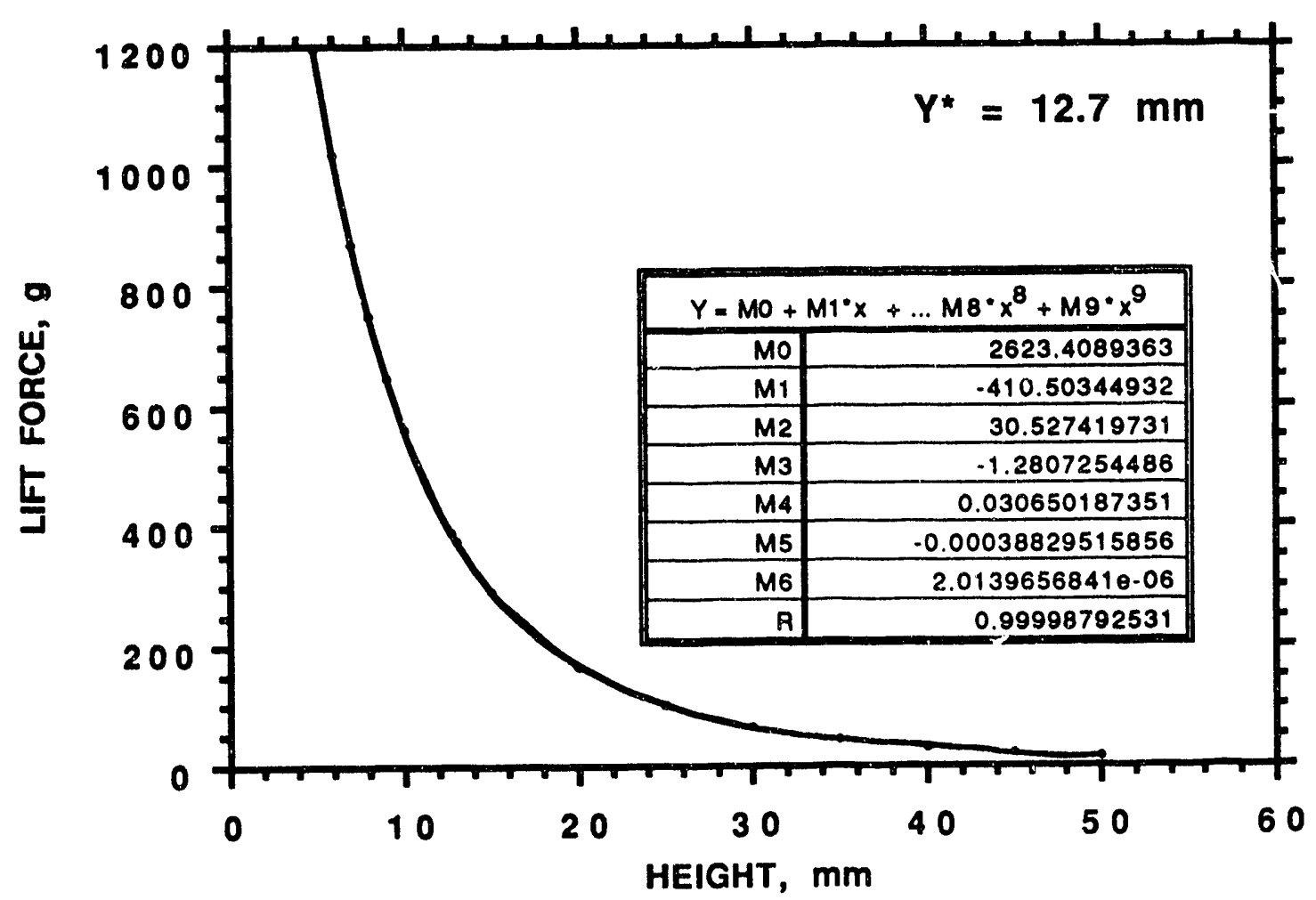

(b)

Fig. 4. Measured lift and guidance magnetic forces 


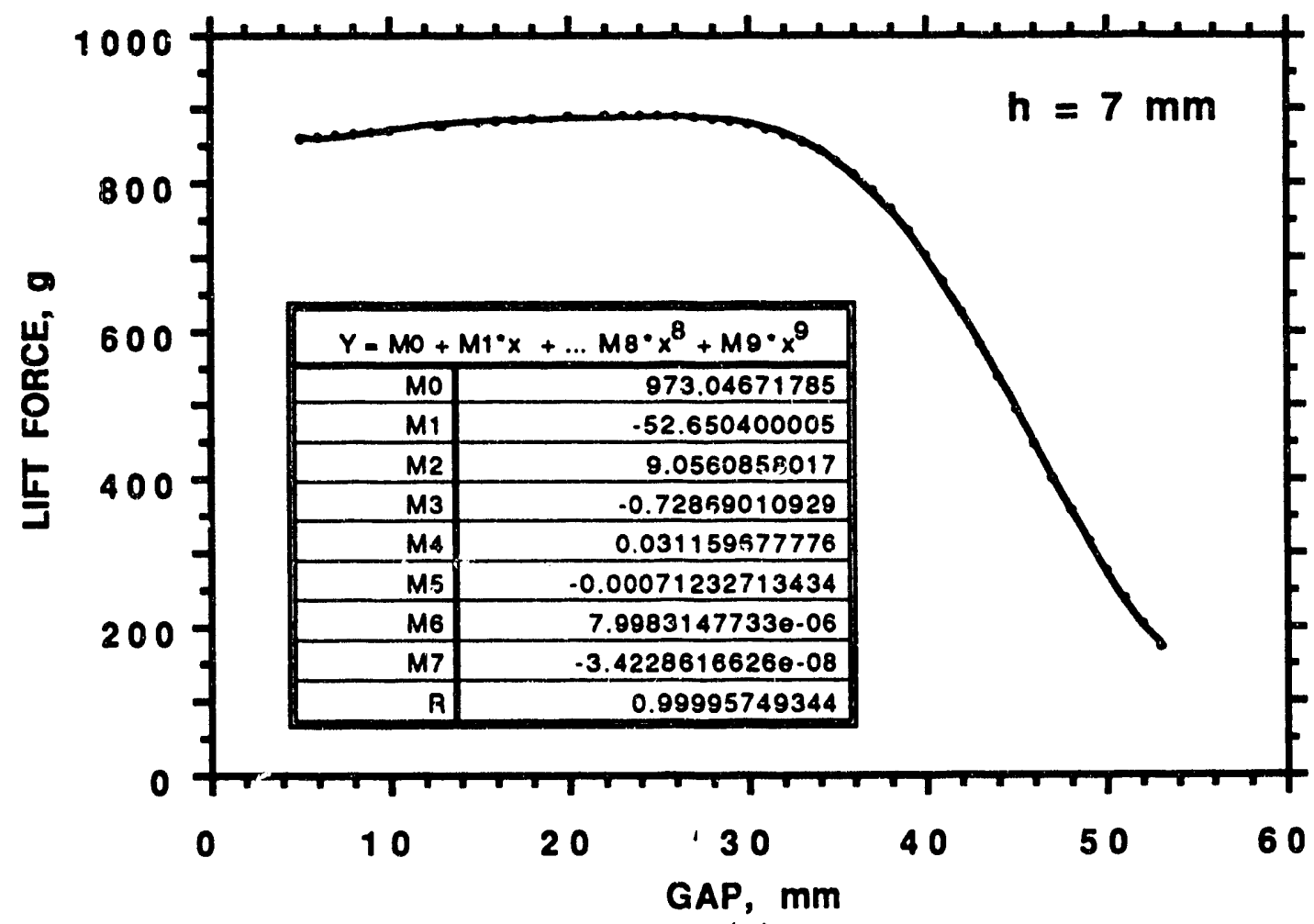

(c)

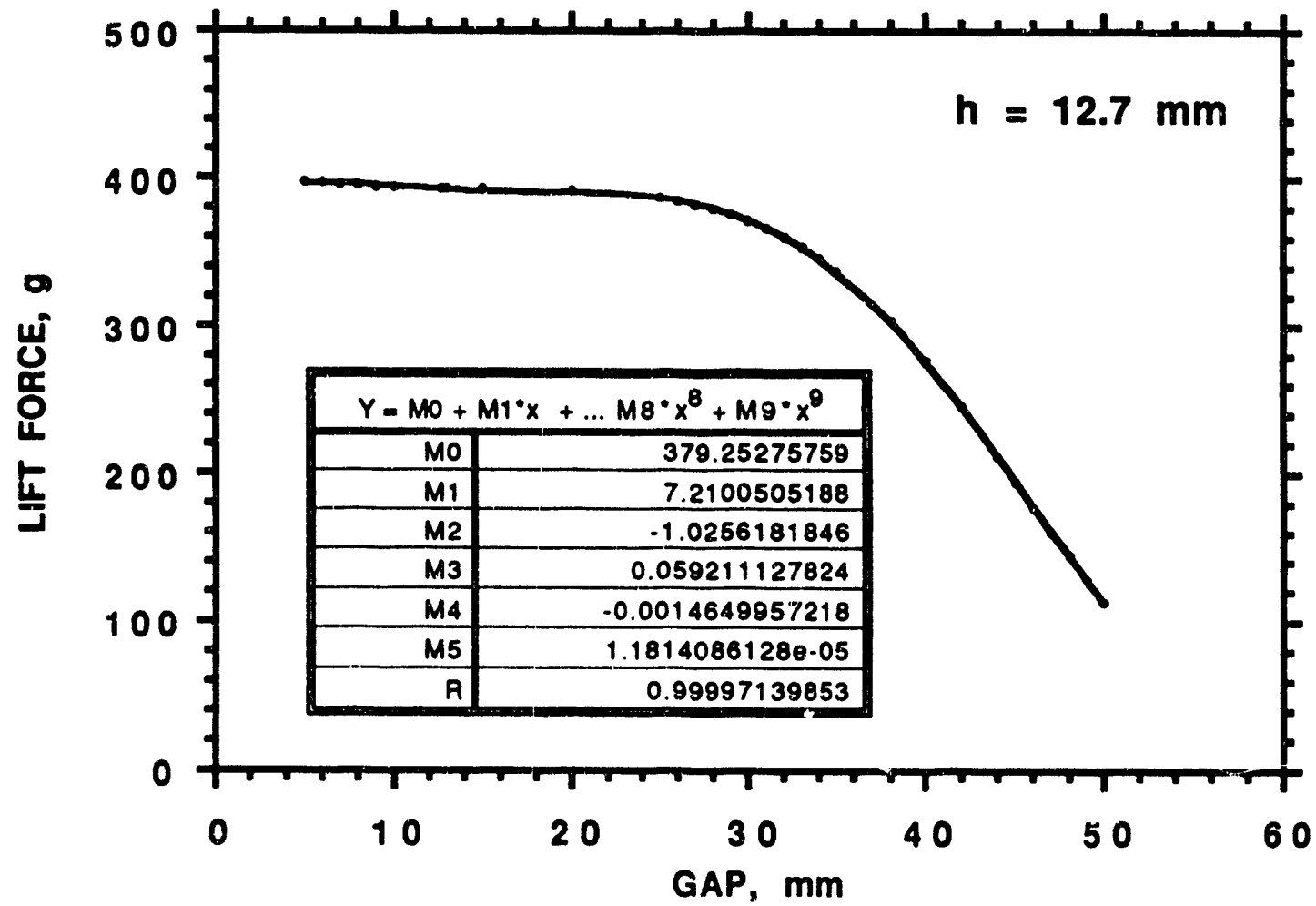

(d)

Fig. 4. Cont'd 


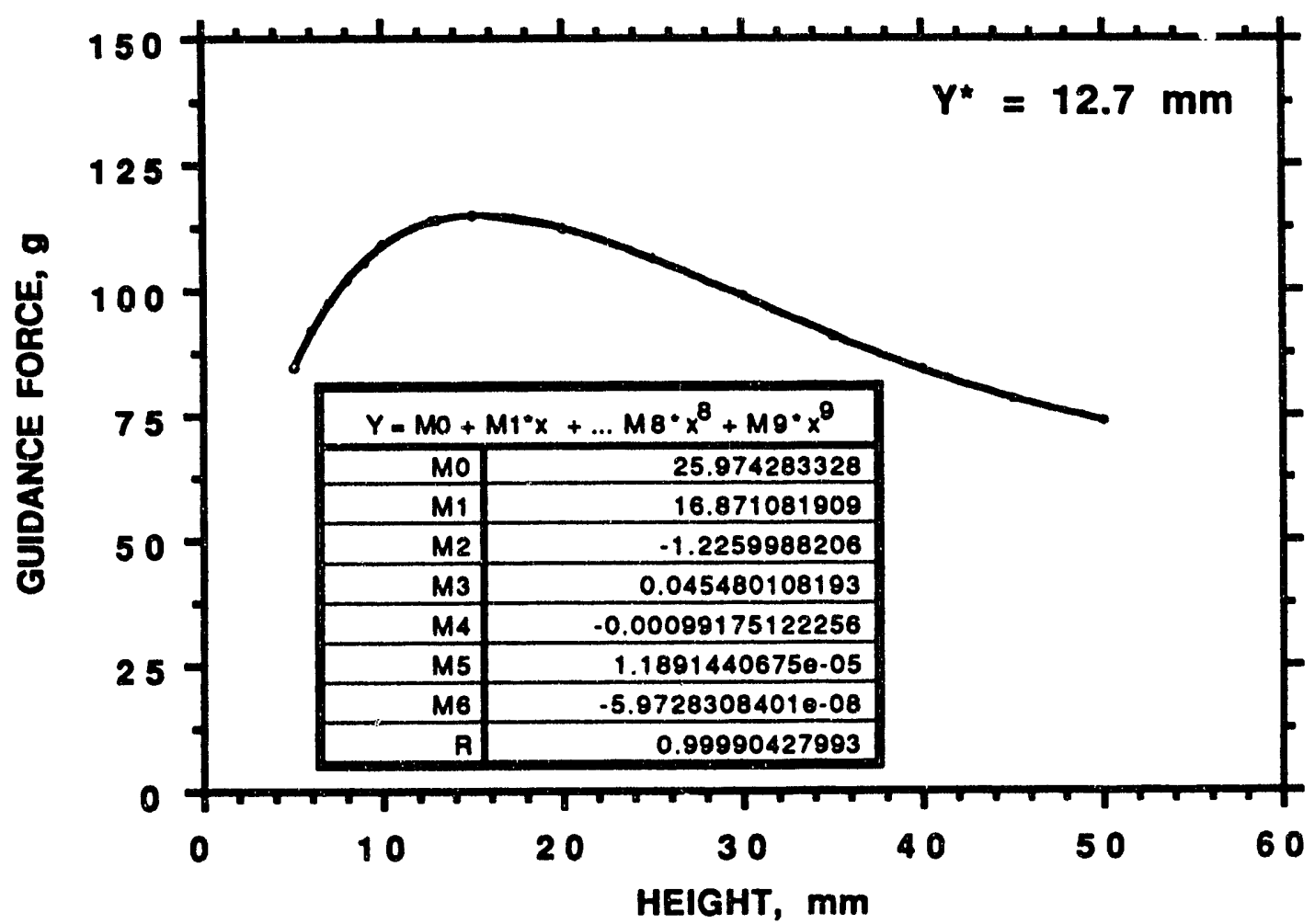

(e)

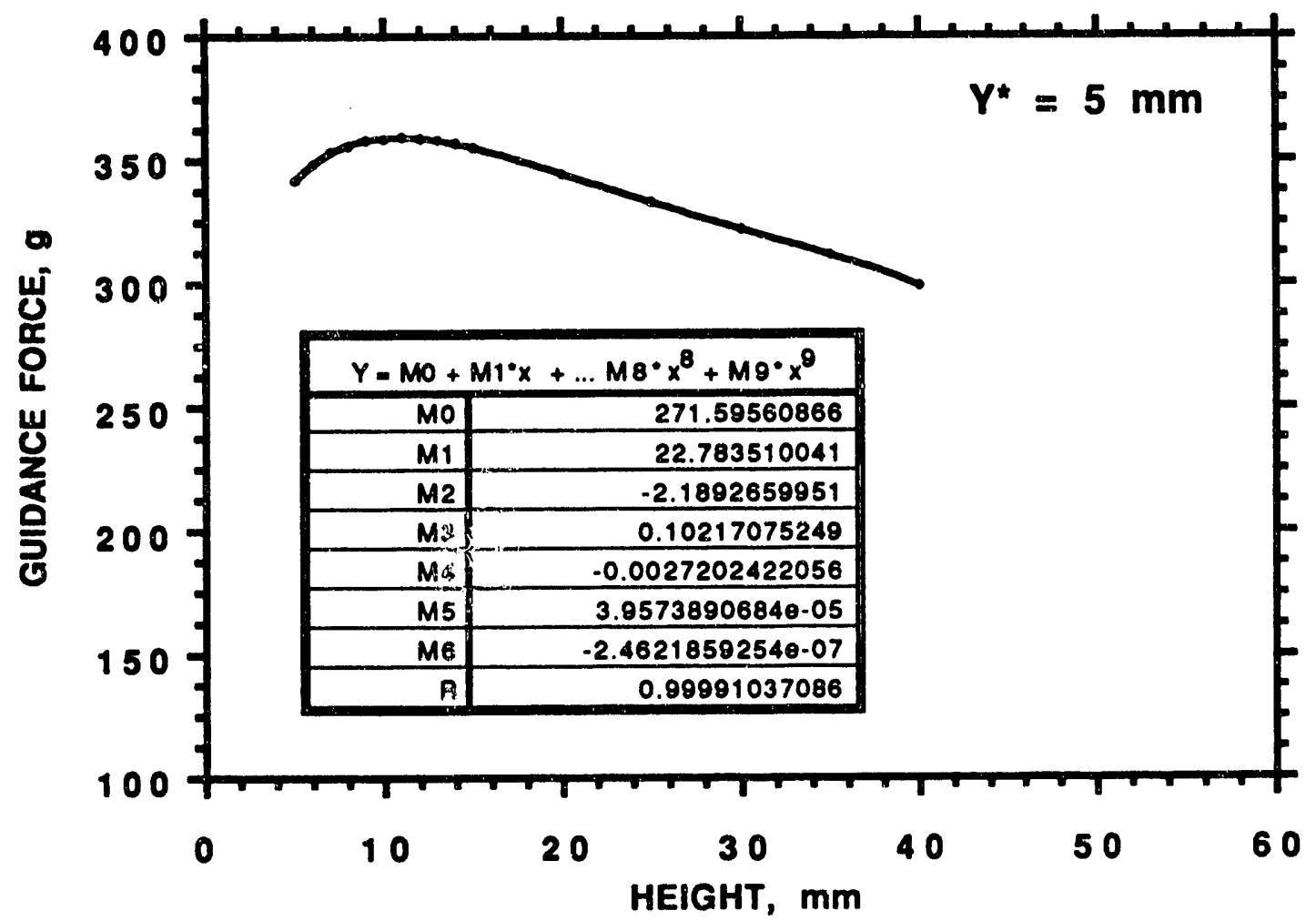

(f)

Fig. 4. Cont'd 


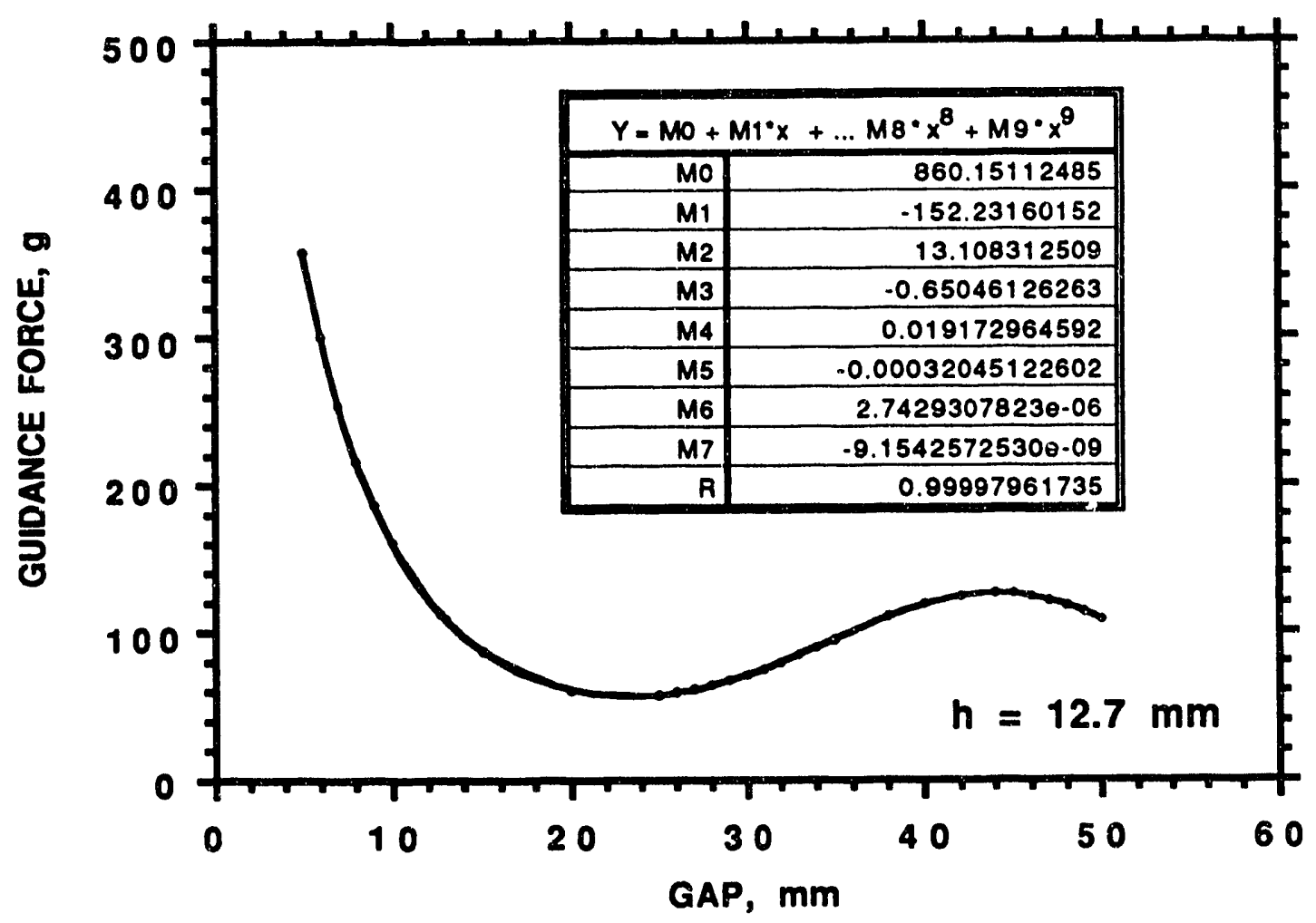

(g)

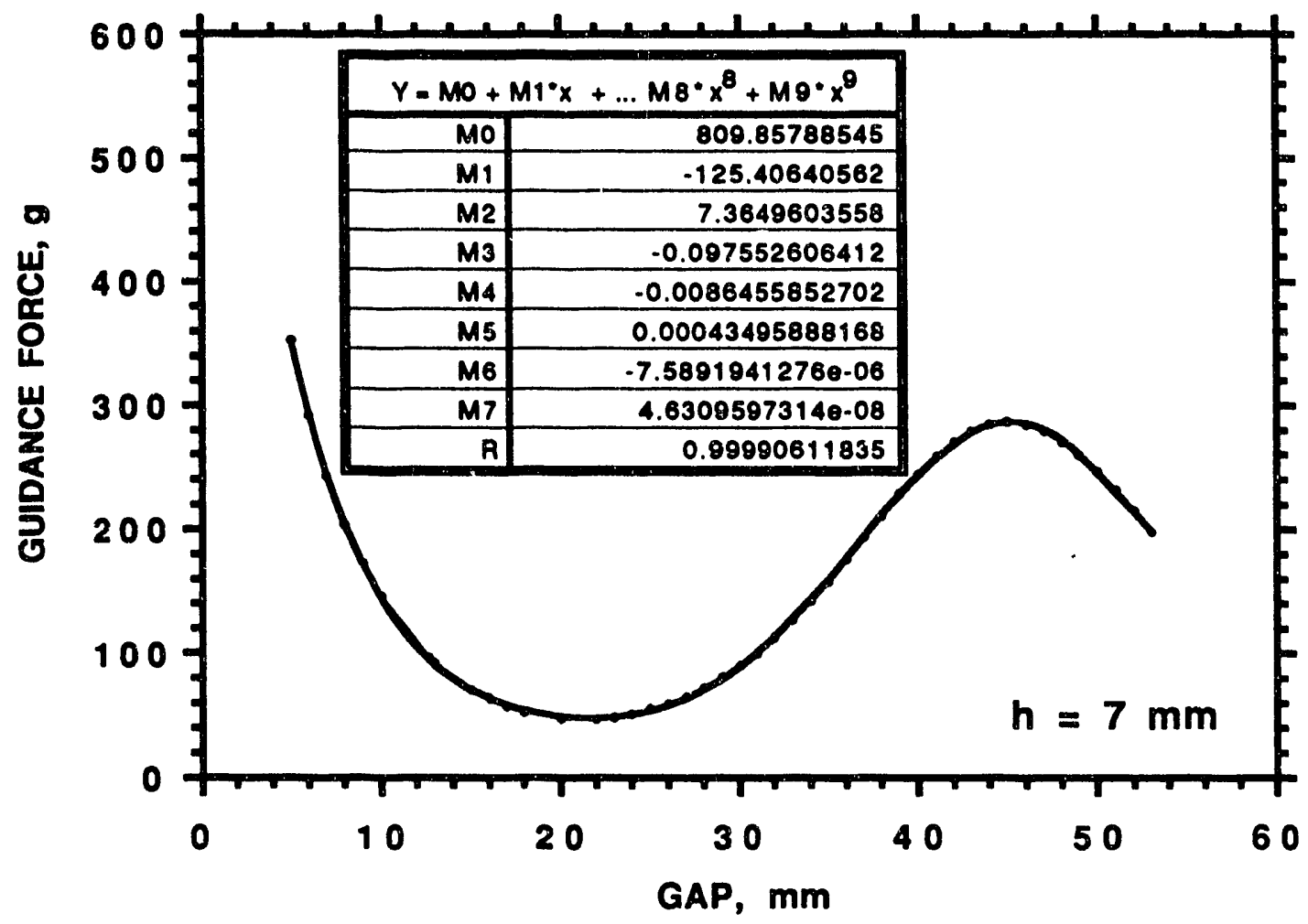

(h)

Fig. 4. Cont'd 
held stationary by a two-component force transducer that comprised two BLH C2G1 load cells connected in series to measure the lift and guidance forces simultaneously. Laboratory weights were used to calibrate the transducer and to assess crosstalk (which was found to be $<2 \%$ ). The base of the load cell assembly was mounted on motorized stages that provided accurate positioning $( \pm 0.05 \mathrm{~mm})$. Out-of-roundness of the L-shaped guideway ring varied, but was always less than $\pm 0.15 \mathrm{~mm}$ for the lateral leg and $\pm 0.35 \mathrm{~mm}$ for the vertical leg. Ability to exactly position the magnet with respect to the guideway dominated our experimental error, estimated at $\pm 5 \%$.

The qualitative trends in the lift and guidance force data taken at lower velocities for the L-shaped guideway are the same as shown in Fig. 4 for the highest velocity tested. Two interesting features are evident. First, a maximum occurs in the guidance force variation with respect to height variations at a fixed gap (as shown in Figs. $4 \mathrm{e}$ and $4 \mathrm{f}$ ) that is caused by the corner region of the guideway. Second, a minimum occurs in the guidance force variation with respect to gap variations at a fixed height (as shown in Figs. $4 \mathrm{~g}$ and $4 \mathrm{~h}$ ) that is caused by the edge of the lateral leg of the guideway. As will be shown in Section 4.4, the first feature is associated with a flutter and the second with a divergence instability.

Based on the magnetic force data shown in Fig. 4, we can calculate the quasistatic motion-dependent magnetic-force coefficients with Eq. 5. All elements of magnetic stiffness $k_{\ell \ell}, k_{\ell g}, k_{g \ell}$, and $k_{g g}$, were calculated and are shown in Fig. 5 with various $\mathrm{Y}^{*}$ and $h$.

The curve fits to both magnetic forces and stiffnesses were derived with polynomial expressions (results are given in Figs. 4 and 5) and input into a computer code to simulate coupled vibrations of the maglev vehicle.

\section{Stability of Maglev Systems}

Without motion-dependent magnetic forces, the equation of motion for the vehicle can be written as

$$
\left[\mathbf{M}_{\mathbf{v}}\right]\{\ddot{\mathrm{U}}\}+\left[\mathrm{C}_{\mathbf{v}}\right]\{\dot{U}\}+\left[\mathrm{K}_{\mathbf{v}}\right]\{\mathrm{U}\}=\{\mathrm{Q}\},
$$

where $M_{v}$ is the vehicle mass matrix, $C_{v}$ is the vehicle damping matrix, $K_{v}$ is the vehicle stiffness matrix, and $Q$ is the generalized excitation force.

The motion-dependent magnetic forces are given in Eq. 3. With motiondependent magnetic forces, Eq. 10 becomes 


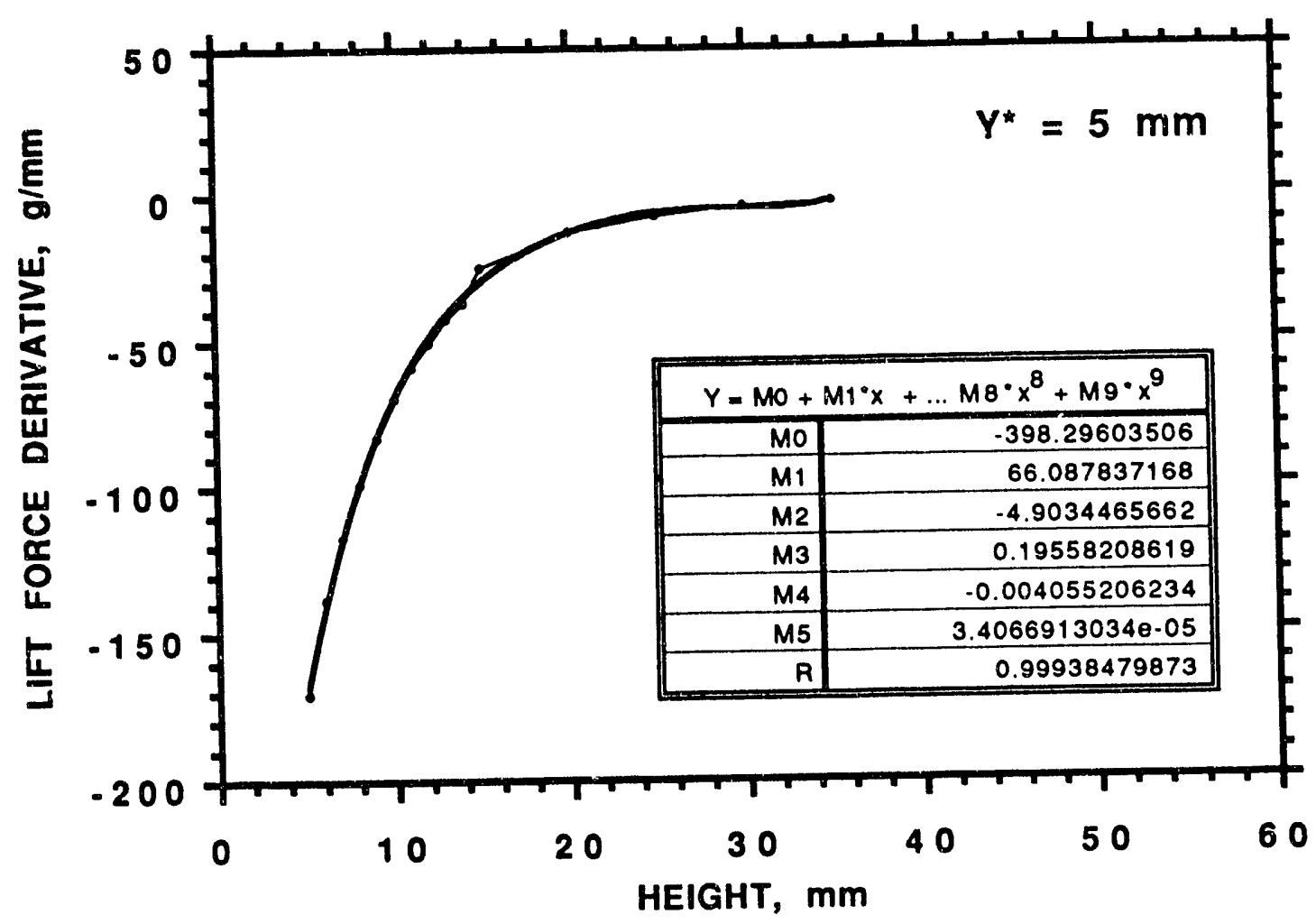

(a)

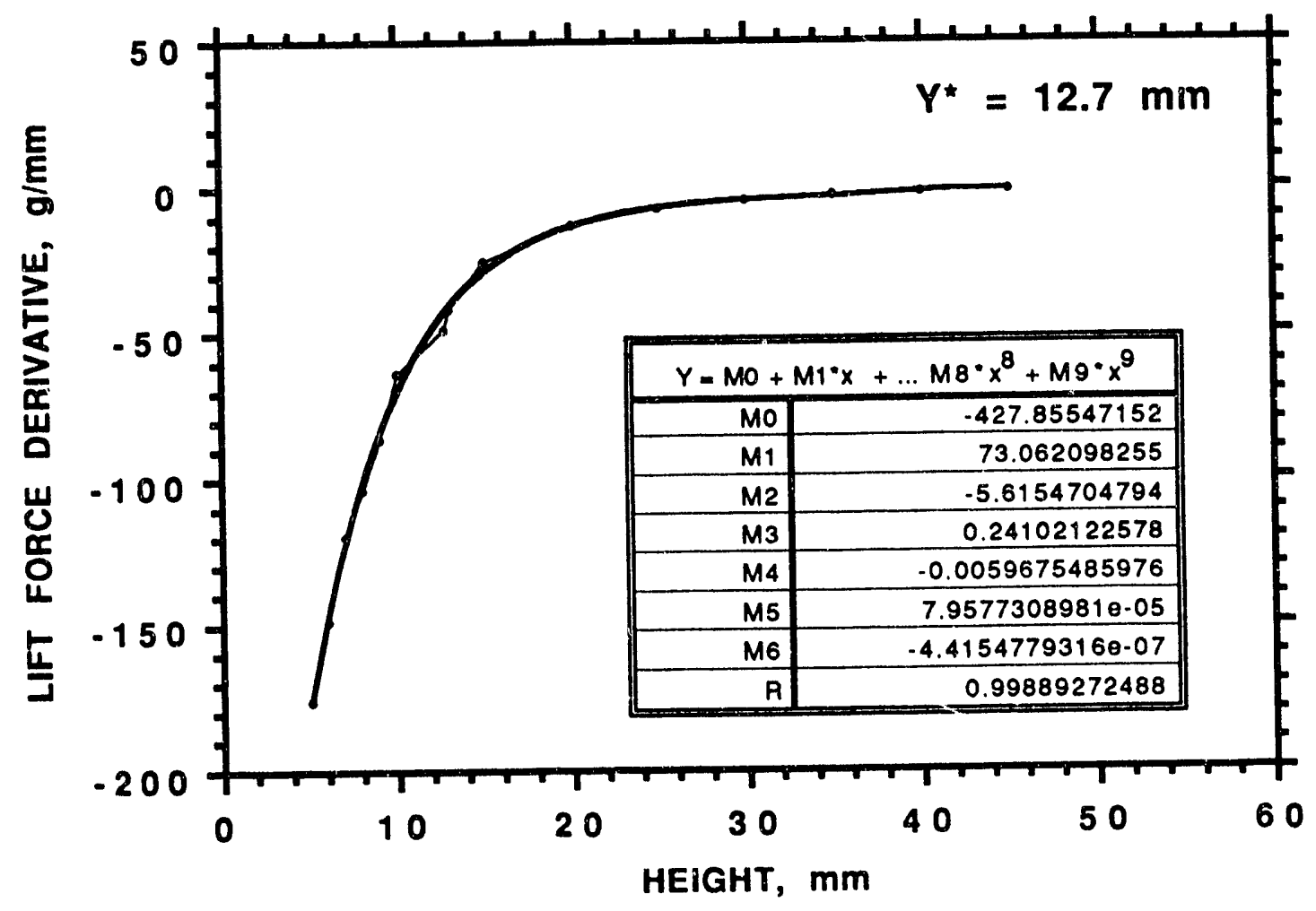

(b)

Fig. 5. Measured lift and guidance magnetic stiffness 


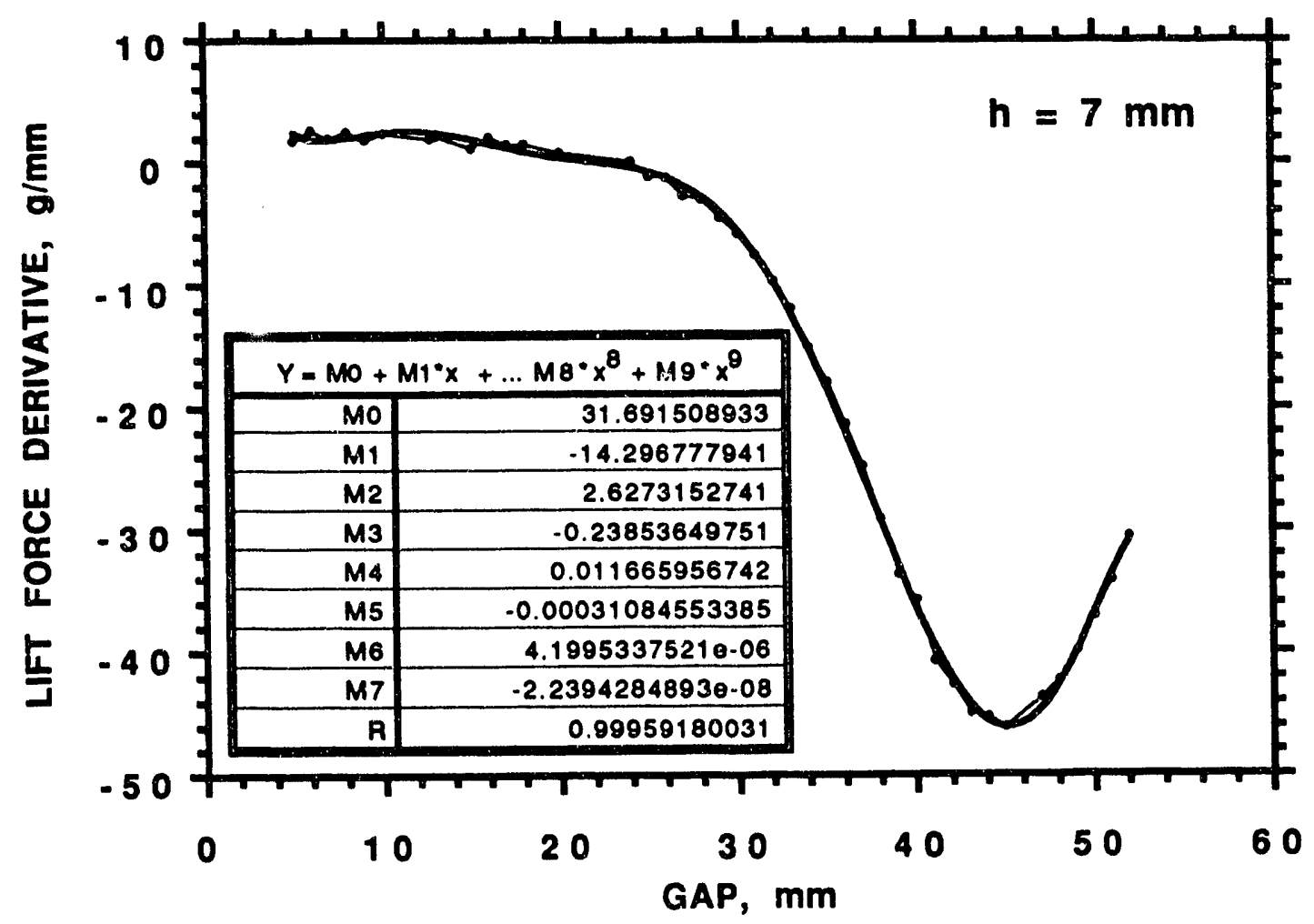

(c)

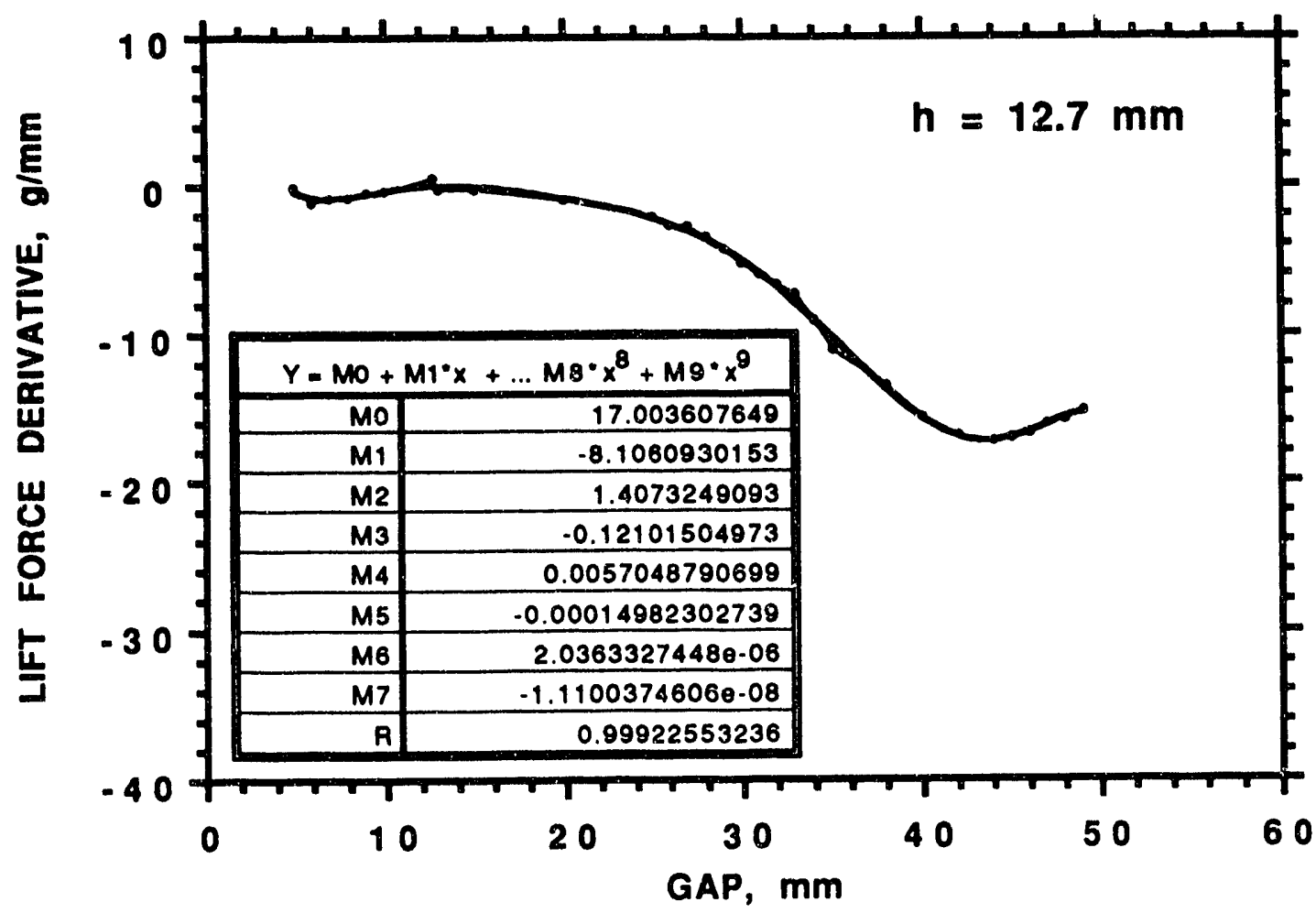

(d)

Fig. 5. Cont'd 


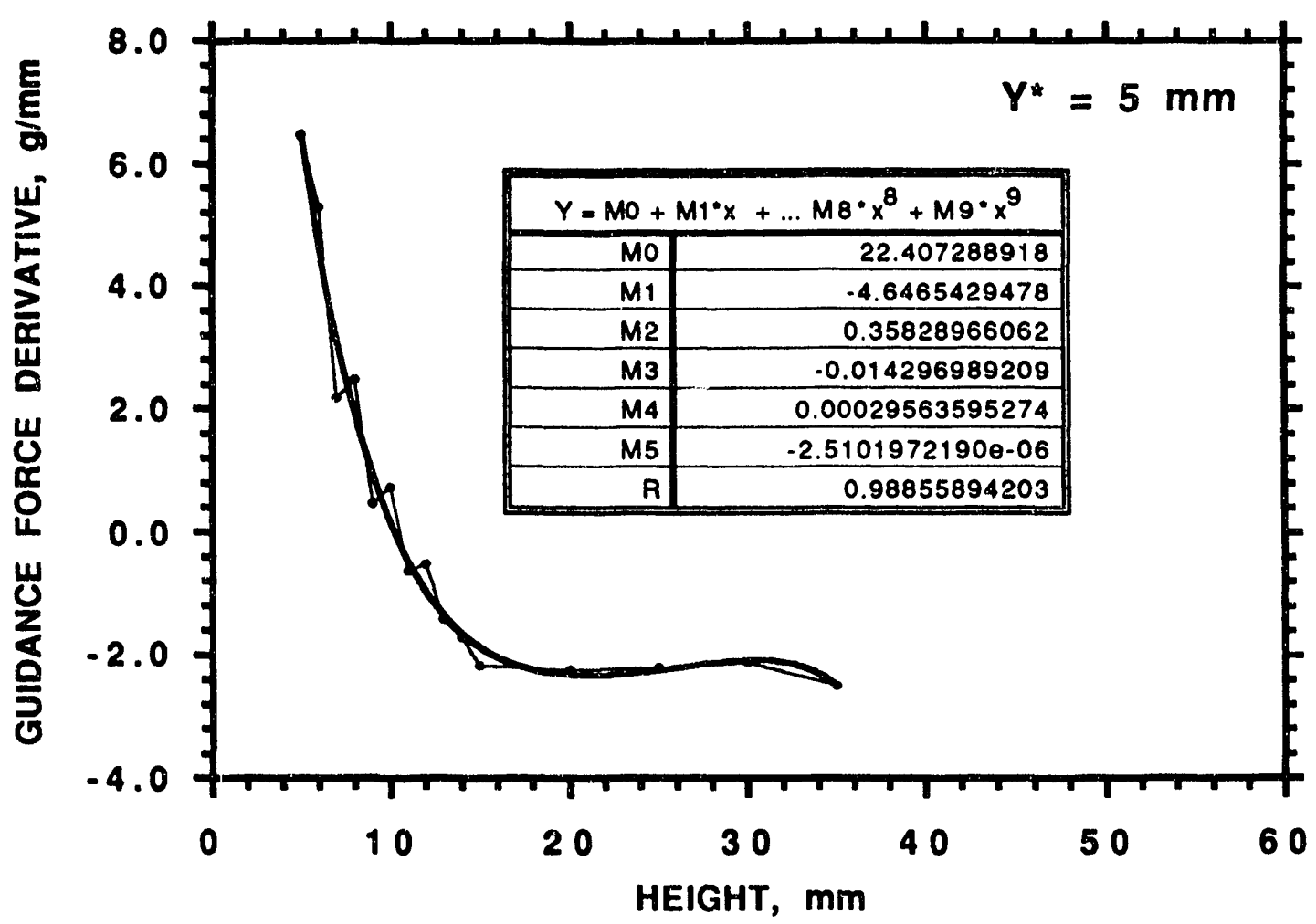

(e)

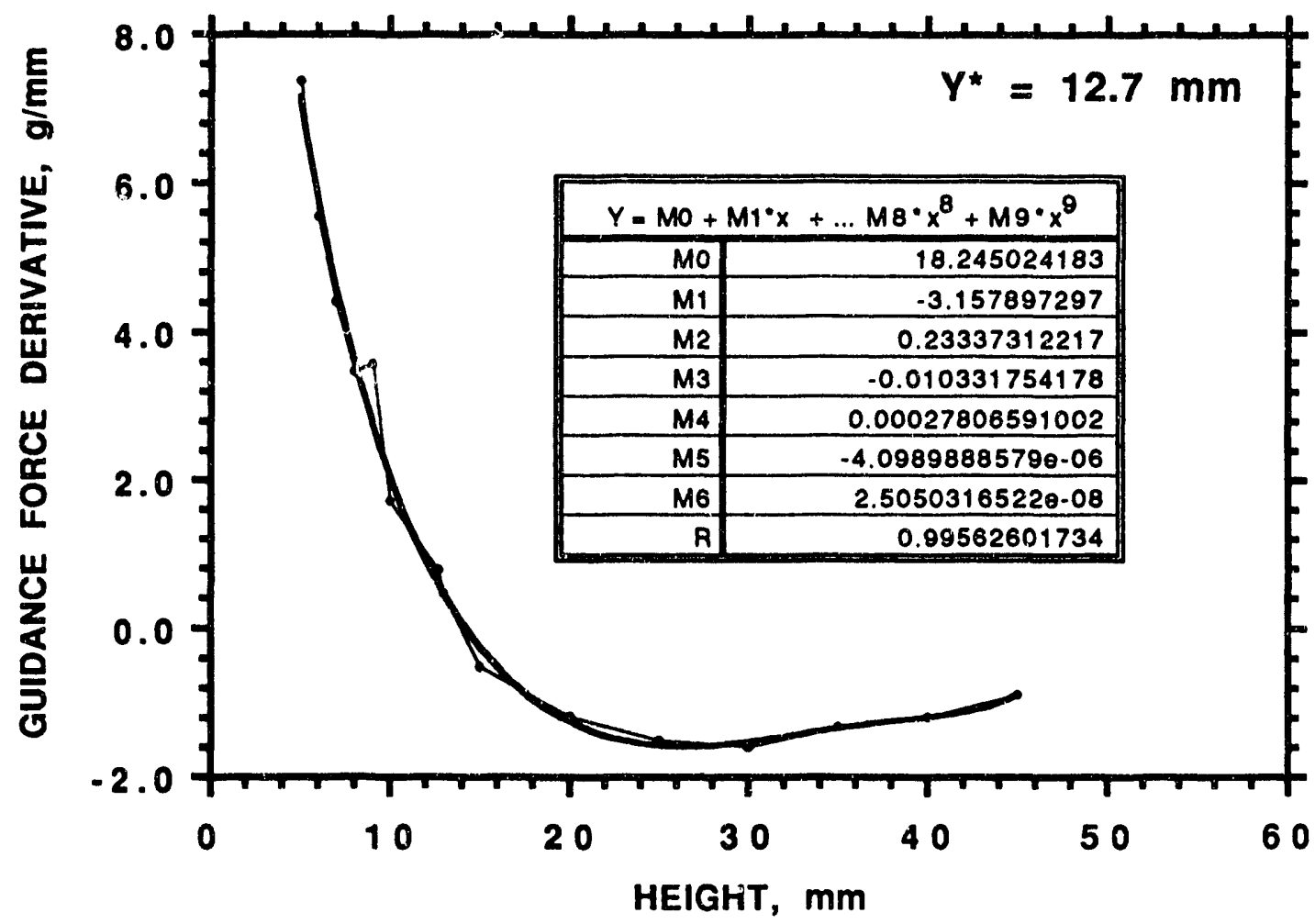

(f)

Fig. 5. Cont'd 


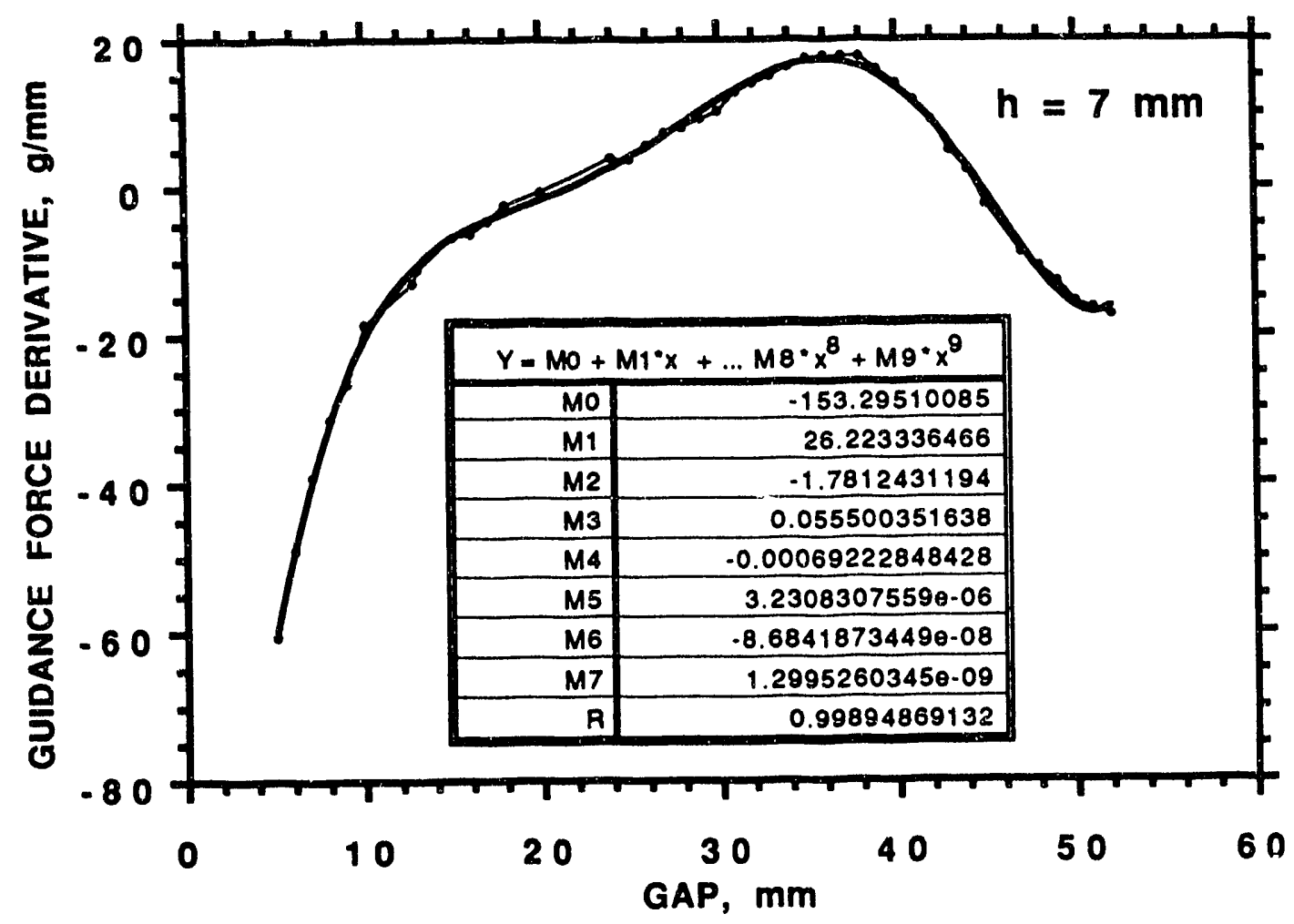

(g)

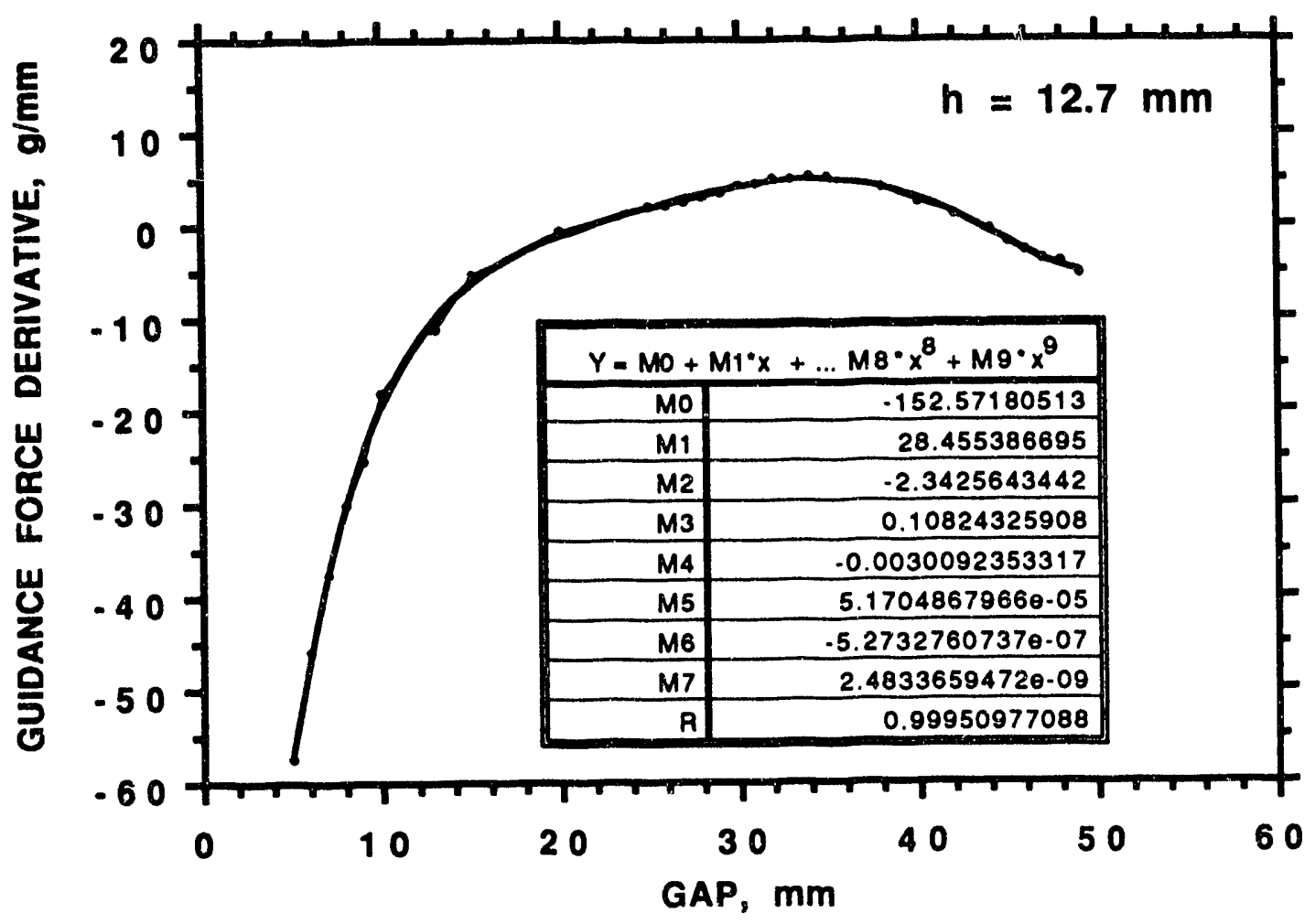

(h)

Fig. 5. Cont'd 


$$
\left[M_{v}+M_{m}\right]\{\ddot{U}\}+\left[C_{v}+C_{m}\right]\{\dot{U}\}+\left[K_{v}+K_{m}\right]\{U\}=\{Q\}
$$

where $M_{m}$ is the magnetic mass matrix, $C_{m}$ is the magnetic damping matrix, and $K_{m}$ is magnetic stiffness; their elements are $m_{i j}$, $c_{i j}$, and $k_{i j}$.

Once the magnetic-force coefficients are known, analysis of vehicle stability is straightforward. Equation 11 may be written as

$$
[\mathrm{M}]\{\ddot{\mathrm{U}}\}+[\mathrm{C}]\{\dot{\mathrm{U}}\}+[\mathrm{K}]\{\mathrm{U}\}=\{\mathrm{Q}\} \text {. }
$$

In general, $M, C$, and $K$ are functions of $U, \dot{U}$, and $\ddot{U}$; therefore, a complete solution is rather difficult to obtain. In many practical situations, one can ignore all nonlinear terms, so that $\mathrm{M}, \mathrm{C}$, and $\mathrm{K}$ are independent of vehicle motion.

By premultiplying by $\{\dot{U}\}^{T}$ and forming the symmetric and antisymmetric components of the matrices

$$
\begin{array}{ll}
{\left[\mathrm{M}_{1}\right]=\frac{1}{2}\left([\mathrm{M}]+[\mathrm{M}]^{\mathrm{T}}\right),} & {\left[\mathrm{M}_{2}\right]=\frac{1}{2}\left([\mathrm{M}]-[\mathrm{M}]^{\mathrm{T}}\right),} \\
{\left[\mathrm{C}_{1}\right]=\frac{1}{2}\left([\mathrm{C}]+[\mathrm{C}]^{\mathrm{T}}\right),} & {\left[\mathrm{C}_{2}\right]=\frac{1}{2}\left([\mathrm{C}]-[\mathrm{C}]^{\mathrm{T}}\right),} \\
{\left[\mathrm{K}_{1}\right]=\frac{1}{2}\left([\mathrm{~K}]+[\mathrm{K}]^{\mathrm{T}}\right),} & {\left[\mathrm{K}_{2}\right]=\frac{1}{2}\left([\mathrm{~K}]-[\mathrm{K}]^{\mathrm{T}}\right),}
\end{array}
$$

the terms may be separated, giving

$$
\begin{aligned}
& \{\dot{U}\}^{\mathrm{T}}\left[\mathrm{M}_{1}\right]\{\ddot{\mathrm{U}}\}+\{\dot{\mathrm{U}}\}^{\mathrm{T}}\left[\mathrm{C}_{2}\right]\{\dot{U}\}+\{\dot{U}\}^{\mathrm{T}}\left[\mathrm{K}_{1}\right]\{\mathrm{U}\} \\
& =-\left(\{\dot{U}\}^{\mathrm{T}}\left[\mathrm{M}_{2}\right]\{\ddot{\mathrm{U}}\}+\{\dot{U}\}^{\mathrm{T}}\left[\mathrm{C}_{1}\right]\{\dot{\mathrm{U}}\}+\{\dot{\mathrm{U}}\}^{\mathrm{T}}\left[\mathrm{K}_{2}\right]\{\mathrm{U}\}\right) .
\end{aligned}
$$

Equation 14 equates rates of work. The terms on the right-hand side of the equation produce a net work-resultant when integrated over a closed path through the space $\{U\}$, the magnitude depending on the path taken. The forces corresponding to the matrices $\mathrm{M}_{2}, \mathrm{C}_{1}$, and $\mathrm{K}_{2}$, appearing on the right-hand side, are thus, by definition, the nonconservative parts of the forces represented by $M$, $\mathrm{C}$, and $\mathrm{K}$. The terms on the left-hand side similarly can be shown to give rise to a zero work-resultant over any closed path, and therefore together are the sum of the rates of work from the potential forces and the rate of change of kinetic energy. 
Different types of instability can be classified according to the dominant terms in Eq. 14:

- Magnetic-Damping-Controlled Instability (single-mode flutter): The dominant terms are associated with the symmetric damping matrix $\left[\mathrm{C}_{1}\right]$. Flutter arises because the magnetic damping forces create "negative damping," that is, a magnetic force that acts in phase with the vehicle velocity.

- Magnetic-Stiffness-Controlled Instability (coupled-mode flutter): The dominant terms are associated with the antisymmetric stiffness matrix $\left[\mathrm{K}_{2}\right]$. It is called coupled-mode flutter because at least two modes are required to produce it.

Corresponding to the single- and coupled-mode flutter, parametric and combination resonances may exist if the motion-dependent magnetic forces are a periodic function of time.

- Parametric Resonance: When the period of a motion-dependent magnetic force is a multiple of one of the natural frequencies of the vehicle, the vehicle may be dynamically unstable.

- Combination Resonance: When the period of the motion-dependent magnetic forces is equal to the sum or difference divided by an integer of the natural frequencies of the vehicle, the vehicle may also be subjected to dynamic instability.

In practical cases, two or more mechanisms may interact with one another, and Eq. 12 is applicable for general cases.

It is noted that maglev systems are subjected to several groups of forces, including magnetic forces, aerodynamic forces, and guideway perturbation. The theory presented in this paper is applicable to maglev systems when they are subjected to other types of forces. In particular, the aerodynamic effects can be described exactly the same way as those given in Eqs. 1-14 and the dynamic response characteristics to aerodynamic forces are similar to magnetic forces; see Chen (1987) for details.

\section{Simplified Vehicle Models for Dynamic Instability}

Four different vehicles are considered, in order to provide an understanding of stability characteristics. 


\subsection{Two-Degree-of-Freeciom Vehicle}

A maglev vehicle is supported by magnetic forces; the resultant lift and drag forces of the coil above the continuous-sheet track can be represented approximately by (Sinha 1987)

$$
\begin{aligned}
& F_{L}(v, z, t)=\varepsilon_{L} F(t), \\
& F_{D}(v, z, t)=\varepsilon_{D} F(t), \\
& F(t)=\mu_{0} I^{2} / 4 \pi z, \\
& \varepsilon_{L}=1-1 /\left(1+v^{2} / w^{2}\right)^{n}, \\
& \varepsilon_{D}=(w / v)\left[1-1 /\left(1+v^{2} / w^{2}\right)^{n}\right], \\
& w=2 / \mu_{0} \sigma h,
\end{aligned}
$$

where $\mathrm{v}$ is the forward velocity, $\mathrm{z}$ is the steady-state height of the coil above the track, $t$ is the time, $I$ is the constant coil current, and $w$ is the characteristic speed and is related to track thickness $h$, conductivity $\sigma$, and permeability $\mu_{0}$. The value of $n$ is 1 for a single conductor and varies from about $1 / 5$ to $1 / 3$ for coils (Rhodes and Mulhall 1981). Note that $F(t)$ represents the repulsive force between the coil and its image coil. The force ratios, $\varepsilon_{L}$ and $\varepsilon_{D}$, are given in Fig. 6 for $n=1,1 / 3$, and $1 / 5$.

Assume that the vehicle is traveling at a velocity $v_{0}$ at an equilibrium height $z_{0}$. The instantaneous position and height of the vehicle are $\mathrm{x}$ and $\mathrm{z}$ respectively; therefore,

$$
\begin{aligned}
& x(t)=v_{0} t+X(t) \\
& z(t)=z_{0}+Z(t)
\end{aligned}
$$

The equations of motion for the vehicle moving at a velocity $v(t)$ with a levitation height $z(t)$ can be written as

$$
\begin{aligned}
& m \ddot{z}(t)=-m g+F_{L}(v, z, t), \\
& m \ddot{x}(t)=F_{p}-F_{D}(v, z, t)-F_{a},
\end{aligned}
$$

where $m$ is the mass of the vehicle, $F_{p}$ is the propulsion force, and $F_{a}$ is the aerodynamic force. The aerodynamic force is given by 


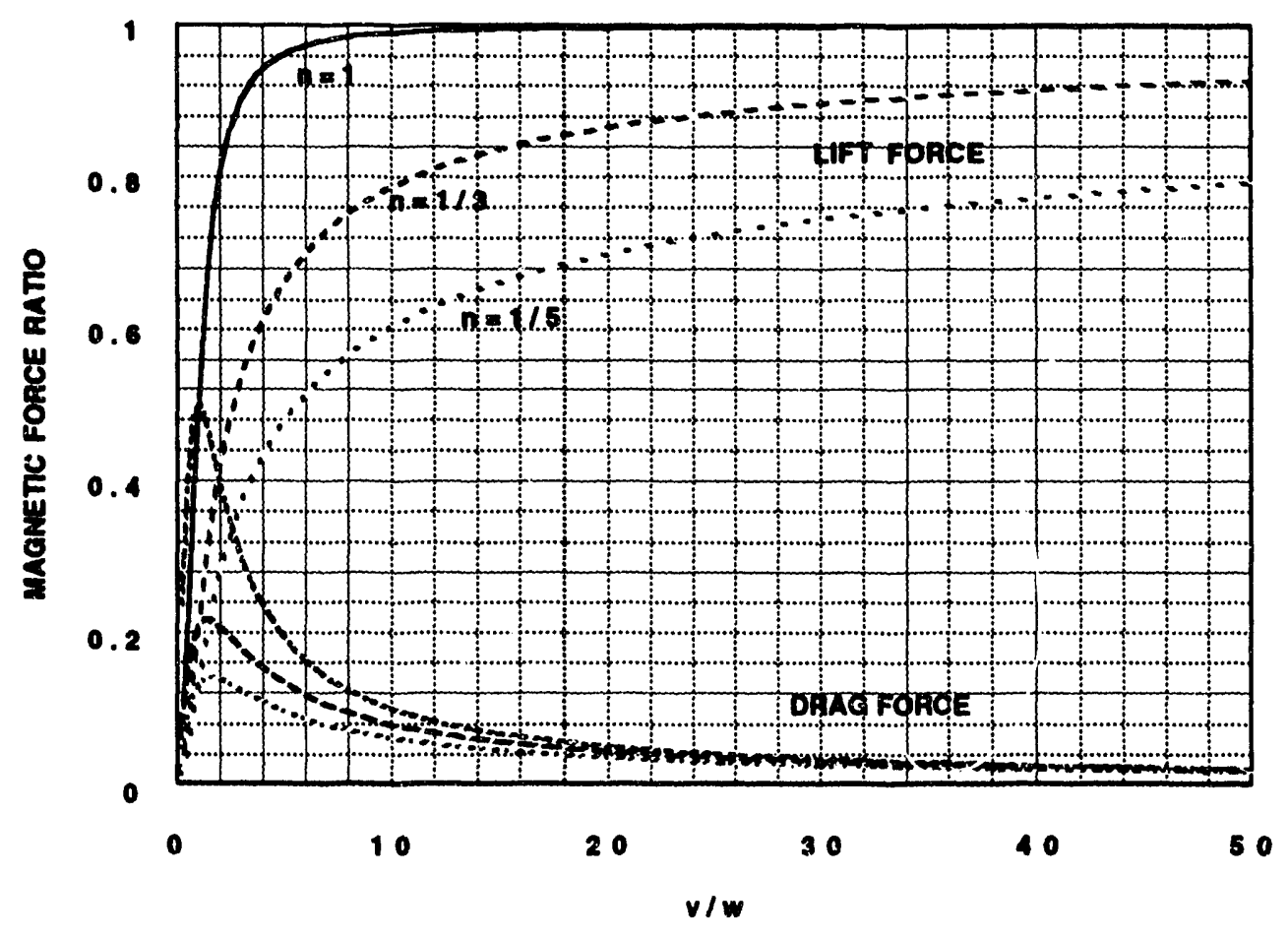

Fig. 6. Magnetic forces divided by image force

$$
\begin{aligned}
& \mathrm{F}_{\mathrm{a}}=\mathrm{K}_{\mathrm{a}} \mathrm{v}^{2}, \\
& \mathrm{~K}_{\mathrm{a}}=0.5 \mathrm{C}_{\mathrm{D}} \text { LAp, }
\end{aligned}
$$

where $L$ and $A$ are the length and cross-sectional area of the vehicle, $\rho$ is air density, $C_{D}$ is the drag coefficient (with its values varying from 0.2 to 0.3 , depending on vehicle shape).

The equilibrium point of the vehicle $v_{0}$ and $z_{0}$ is defined by

$$
\begin{aligned}
& F_{L}\left(v_{0}, z_{0}\right)=m g, \\
& F_{D}\left(v_{0}, z_{0}\right)=F_{p}-F_{a} .
\end{aligned}
$$

Using Eqs. 16-19 and neglecting the nonlinear terms, we obtain the following equations of motion for the vehicle $\mathrm{X}(\mathrm{t})$ and $\mathrm{Z}(\mathrm{t})$ :

$$
\begin{aligned}
& m \ddot{Z}(t)-C_{z x}(v, z, t) \dot{X}(t)+K_{z z}(v, z, t) Z(t)=0, \\
& m \ddot{X}(t)+C_{x x}(v, z, t) \dot{X}(t)-K_{x z}(v, z, t) Z(t)=0 .
\end{aligned}
$$


$\mathrm{C}_{\mathrm{zx}}(\mathrm{v}, \mathrm{z}, \mathrm{t})$ and $\mathrm{C}_{\mathrm{xx}}(\mathrm{v}, \mathrm{z}, \mathrm{t})$ are magnetic damping, and $\mathrm{K}_{\mathrm{zz}}(\mathrm{v}, \mathrm{z}, \mathrm{t})$ and $\mathrm{K}_{\mathrm{xz}}(\mathrm{v}, \mathrm{z}, \mathrm{t})$ are magnetic stiffness; these are given by

$$
\begin{aligned}
& \mathrm{C}_{\mathrm{zx}}(\mathrm{v}, \mathrm{z}, \mathrm{t})=\partial \mathrm{F}_{\mathrm{L}}(\mathrm{v}, \mathrm{z}, \mathrm{t}) /\left.\partial \mathrm{v}\right|_{\left(\mathrm{v}_{0}, \mathrm{z}_{0}\right)}, \\
& \mathrm{C}_{\mathbf{x x}}(\mathrm{v}, \mathrm{z}, \mathrm{t})=\partial \mathrm{F}_{\mathrm{D}}(\mathrm{v}, \mathrm{z}, \mathrm{t}) /\left.\partial \mathrm{v}\right|_{\left(\mathrm{v}_{0}, \mathrm{z}_{0}\right)}+2 \mathrm{~K}_{\mathrm{a}} \mathrm{v}_{0}, \\
& \mathrm{~K}_{\mathrm{zz}}(\mathrm{v}, \mathrm{z}, \mathrm{t})=-\partial \mathrm{F}_{\mathrm{L}}(\mathrm{v}, \mathrm{z}, \mathrm{t}) /\left.\partial \mathrm{z}\right|_{\left(\mathrm{v}_{0}, \mathrm{z}_{0}\right)}, \\
& \mathrm{K}_{\mathrm{xz}}(\mathrm{v}, \mathrm{z}, \mathrm{t})=-\partial \mathrm{F}_{\mathrm{D}}(\mathrm{v}, \mathrm{z}, \mathrm{t}) /\left.\partial \mathrm{z}\right|_{\left(\mathrm{v}_{0}, \mathrm{z}_{0}\right)}
\end{aligned}
$$

Their values are given as follows:

$$
\begin{aligned}
& \mathrm{C}_{\mathrm{zx}}=\left(\mathrm{mg} / \varepsilon_{\mathrm{L}}\right) 2 \mathrm{nv}_{0} /\left[\mathrm{w}^{2}\left(1+\mathrm{v}_{0}^{2} / \mathrm{w}^{2}\right)^{\mathrm{n}+1}\right], \\
& \mathrm{C}_{\mathrm{xx}}=\mathrm{wmg} / \mathrm{v}_{0}^{2}\left[\mathrm{w}^{2}-(2 \mathrm{n}-1) \mathrm{v}_{0}^{2} /\left(\mathrm{w}^{2}+\mathrm{v}_{0}^{2}\right)\right]+2 \mathrm{~K}_{\mathrm{a}} \mathrm{v}_{0}, \\
& \mathrm{~K}_{\mathrm{zz}}=\mathrm{mg} / \mathrm{z}_{0}, \\
& \mathrm{~K}_{\mathrm{xz}}=\mathrm{wmg} / \mathrm{v}_{0} \mathrm{z}_{0} .
\end{aligned}
$$

For high speed vehicles, the values of $\mathrm{C}_{\mathrm{zx}}$ and $\mathrm{K}_{\mathrm{xz}}$ are approximately zero. Therefore, the motions in the vertical direction and forward direction are uncoupled at high speeds.

Equations 20 can be analyzed; let

$$
\begin{aligned}
& Z(t)=a \exp (i \omega t) \\
& X(t)=b \exp (i \omega t)
\end{aligned}
$$

Substituting Eqs. 23 into Eqs. 20 gives the following frequency equation:

$$
\left[\begin{array}{ll}
-m \omega^{2}+\mathrm{K}_{\mathrm{zz}} & -\mathrm{i} \omega \mathrm{C}_{\mathrm{zx}} \\
-\mathrm{K}_{\mathrm{xz}} & -\mathrm{m} \omega^{2}+\mathrm{i} \omega \mathrm{C}_{\mathrm{xx}}
\end{array}\right]\left\{\begin{array}{l}
\mathrm{a} \\
\mathrm{b}
\end{array}\right\}=\left\{\begin{array}{l}
0 \\
0
\end{array}\right\}
$$

The natural frequencies can be determined from the determinant of the coefficient matrix given in Eq. 24. At high speeds, the off-diagonal terms may be neglected. The natural frequency of the vertical motion $f_{v}$ is

$$
f_{v}=\left(g / z_{0}\right)^{0.5 / 2 \pi}
$$




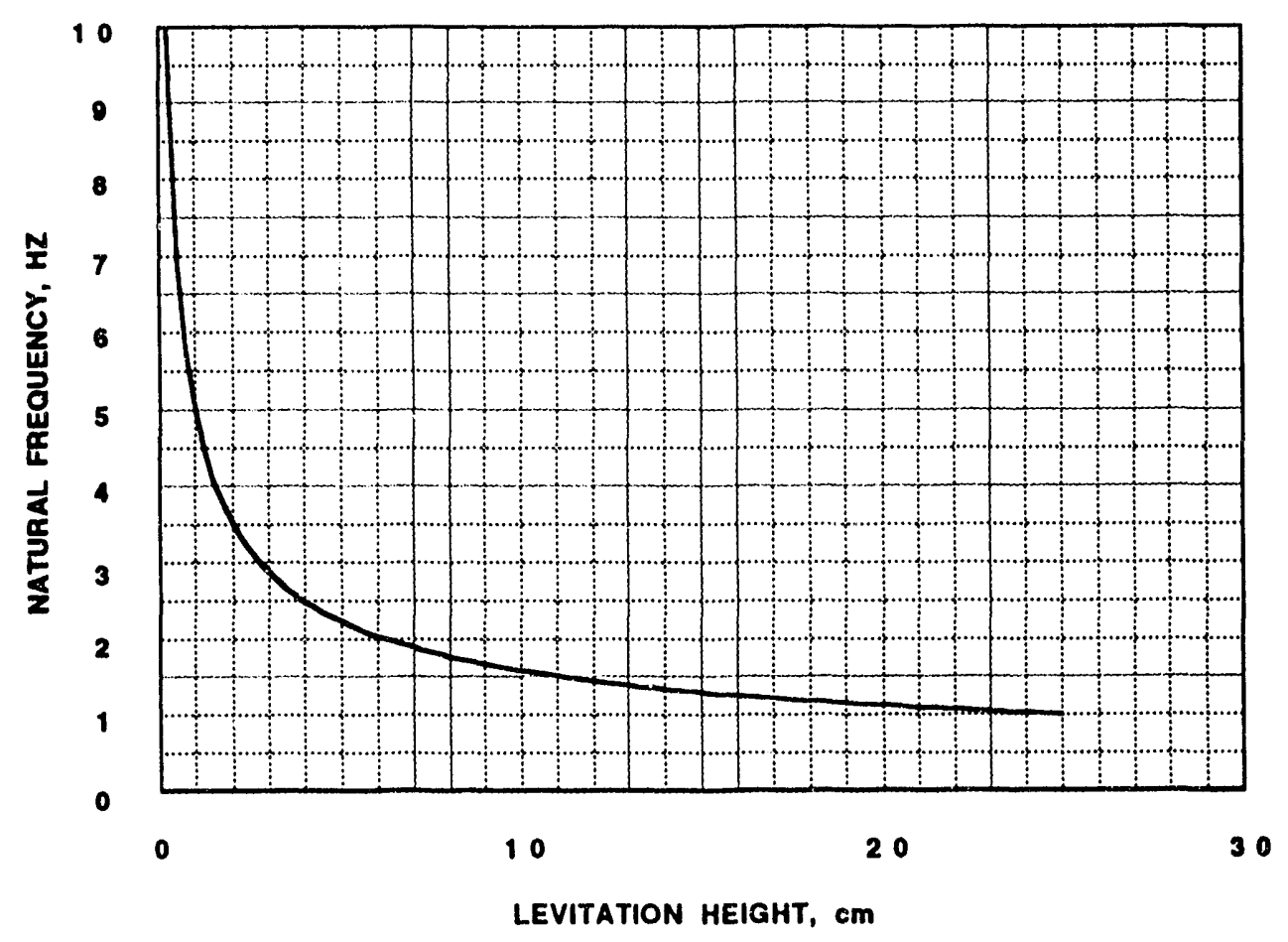

Fig. 7. Natural frequency as a function of levitation height

The natural frequency in the vertical direction depends on the levitation height only. Figure 7 shows the natural frequency as a function of the levitation height. At high speeds, oscillations in the vertical direction are stable.

In the forward direction, the motion is given by

$$
X(t)=C_{1}+C_{2} \exp (s t) .
$$

For high-speed vehicles, the exponent $\mathrm{s}$ is approximately given by

$$
s=(2 n-1) w g / v_{0}^{2}-2 K_{a} v_{0} .
$$

Note that the vehicle may be unstable if $n=1$, and $K_{a}$ is zero. At high speeds, the second term given in Eq. 27 is larger than the first term regardless of the values of $\mathrm{n}$; therefore, $\mathrm{s}$ is negative and the system is stable.

\subsection{Three-Degree-of-Freedom Vehicle}

Figure 8 shows a three-degree-of-freedom vehicle traveling at a velocity $v_{0}$ at an equilibrium height $z_{0}$. For a symmetric vehicle, the instantaneous position and height of the vehicle are $x(t), z_{1}(t)$, and $z_{2}(t)$; therefore, 

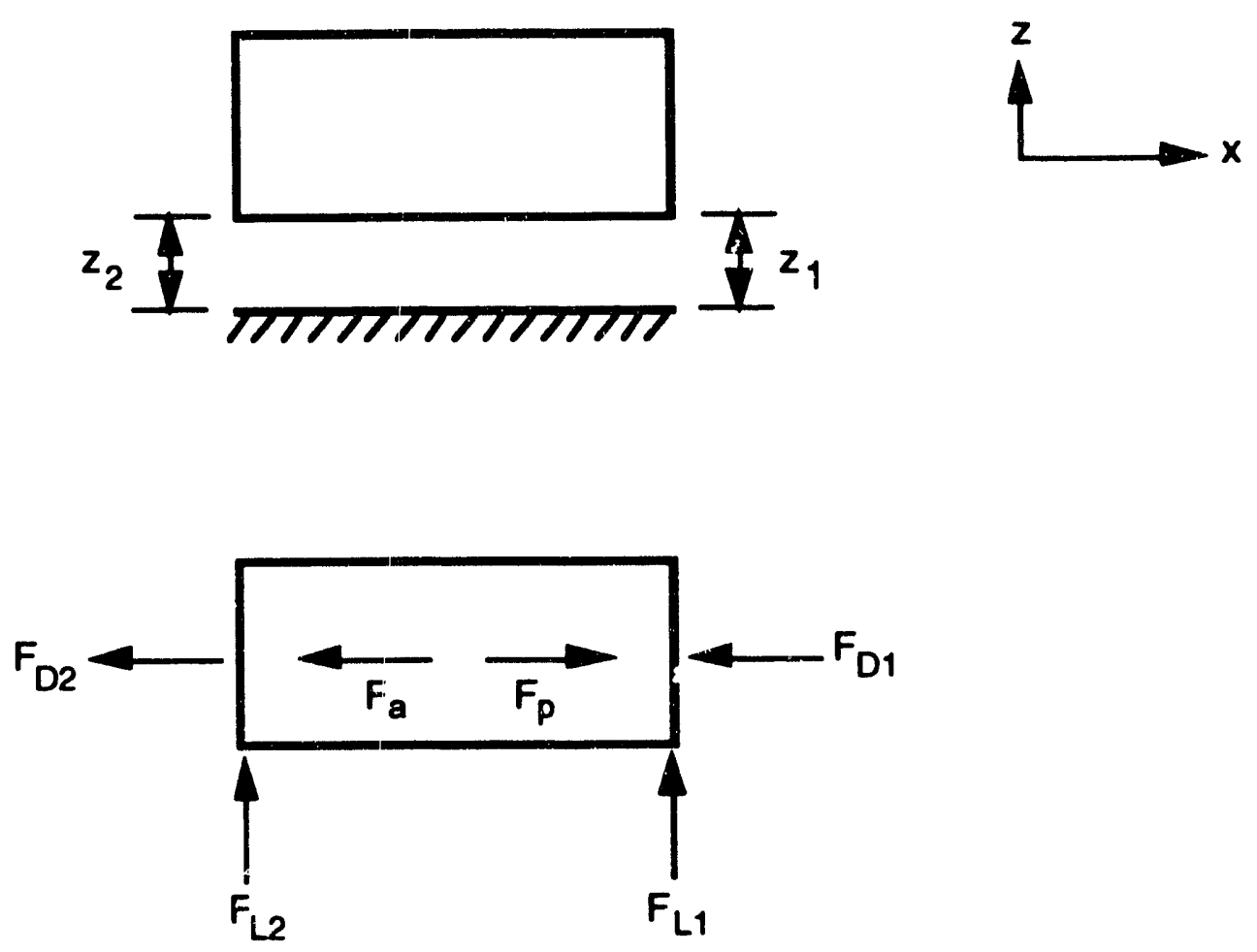

Fig. 8. Three-degree-of-freedom vehicle

$$
\begin{aligned}
& x(t)=v_{0}(t)+X(t), \\
& z_{1}(t)=z_{0}+Z_{1}(t), \\
& z_{2}(t)=z_{0}+Z_{2}(t) .
\end{aligned}
$$

The equations of motion for the vehicle moving at a velocity $v(t)$ with levitation height $z_{1}(t)$ and $z_{2}(t)$ can be written as

$$
\begin{aligned}
& m \ddot{x}(t)=F_{p}-F_{D 1}\left(z_{1}, v, t\right)-F_{D 2}\left(z_{2}, v, t\right)-F_{a}, \\
& \frac{m}{2}\left[\ddot{z}_{1}(t)+\ddot{z}_{2}(t)\right]=-m g+F_{L 1}\left(z_{1}, v, t\right)+F_{L 2}\left(z_{2}, v, t\right), \\
& \frac{I_{\theta}}{L}\left[\ddot{z}_{1}(t)-\ddot{z}_{2}(t)\right]=\frac{L}{2}\left[F_{L 1}\left(z_{1}, v, t\right)-F_{L 2}\left(z_{2}, v, t\right)\right] .
\end{aligned}
$$

where $\mathrm{m}$ is the vehicle mass, $I_{\theta}$ is the rotational moment of inertia about the vehicle's center of mass, $F_{p}$ is the propulsion force, and $F_{a}$ is the aerodynamic force that is assumed to act at the center of mass of the vehicle and is given by Eq. 18. 
For a symmetric vehicle with two identical levitation systems at the two ends, the equilibrium point of the vehicle $v_{0}, z_{10}$, and $z_{20}$, as well as the magnetic forces, is defined as

$$
\begin{aligned}
& F_{L 1}\left(v_{0}, z_{10}\right)+F_{L 2}\left(v_{0}, z_{20}\right)=m g, \\
& F_{D 1}\left(v_{0}, z_{10}\right)+F_{D 2}\left(v_{0}, z_{20}\right)=F_{p}-F_{a}, \\
& z_{10}=z_{20}=z_{0}, \\
& F_{L 1}\left(v_{0}, z_{10}\right)=F_{L 2}\left(v_{0}, z_{20}\right), \\
& F_{D 1}\left(v_{0}, z_{20}\right)=F_{D 2}\left(v_{0}, z_{20}\right) .
\end{aligned}
$$

Using Eqs. 28, 29, 30, and 18 and neglecting the nonlinear terms, we obtain the following equations of motion of the vehicle, $X(t), Z_{1}(t)$, and $Z_{2}(t)$ :

$$
\begin{aligned}
& \frac{\mathrm{m}}{2}\left(\ddot{\mathrm{Z}}_{1}+\ddot{\mathrm{Z}}_{2}\right)+\left(\mathrm{C}_{\mathrm{zx} 1}+\mathrm{C}_{\mathrm{zx} 2}\right) \dot{\mathrm{X}}+\mathrm{K}_{\mathrm{zz} 1} \mathrm{Z}_{1}+\mathrm{K}_{\mathrm{zz} 2} \mathrm{Z}_{2}=0 \\
& \frac{2 \mathrm{I}_{\theta}}{\mathrm{L}^{2}}\left(\ddot{\mathrm{z}}_{1}-\ddot{\mathrm{z}}_{2}\right)+\left(\mathrm{C}_{\mathrm{zx} 1}-\mathrm{C}_{\mathrm{zx} 2}\right) \dot{\mathrm{X}}+\left(\mathrm{K}_{\mathrm{zz} 1} \mathrm{Z}_{1}-\mathrm{K}_{\mathrm{zz} 2} \mathrm{Z}_{2}=0\right. \\
& \mathrm{m} \ddot{\mathrm{X}}+\left(\mathrm{C}_{\mathrm{xx} 1}+\mathrm{C}_{\mathrm{xx} 2}+2 \mathrm{k}_{\mathrm{a}} \mathrm{v}_{0}\right) \dot{\mathrm{X}}+\mathrm{K}_{\mathrm{xz} 1} \mathrm{Z}_{1}+\mathrm{K}_{\mathrm{xz2} 2} \mathrm{Z}_{2}=0
\end{aligned}
$$

where

$$
\begin{aligned}
& \mathrm{C}_{\mathrm{zxi}}=-\left.\frac{\partial \mathrm{F}_{\mathrm{Li}}}{\partial \mathrm{v}}\right|_{\left(\mathrm{v}_{0}, \mathrm{z}_{0}\right)} \\
& \mathrm{C}_{\mathbf{x x i}}=\left.\frac{\partial \mathrm{F}_{\mathrm{Di}}}{\partial \mathrm{v}}\right|_{\left(\mathrm{v}_{0}, \mathrm{z}_{0}\right)} \\
& \mathrm{K}_{\mathrm{zzi}}=-\left.\frac{\partial \mathrm{F}_{\mathrm{Li}}}{\partial \mathrm{z}_{\mathrm{i}}}\right|_{\left(\mathrm{v}_{0}, \mathrm{z}_{0}\right)} \\
& \mathrm{K}_{\mathrm{xzi}}=\left.\frac{\partial \mathrm{F}_{\mathrm{Di}}}{\partial \mathrm{z}_{\mathrm{i}}}\right|_{\left(\mathrm{v}_{0}, \mathrm{z}_{0}\right)} \\
& \mathrm{i}=1,2 .
\end{aligned}
$$


The magnetic damping coefficients $\mathrm{C}_{\mathrm{zxi}}$ and $\mathrm{C}_{\mathrm{xxi}}$, and the magnetic stiffness coefficients $K_{z z i}$ and $K_{x z i}$ can be calculated from the magnetic lift and drag forces given in Eq. 15.

At high speeds, $K_{z x i}$ and $C_{x z i}$ are approximately zero, The equations of motion become

$$
\begin{aligned}
& \frac{\mathrm{m}}{2}\left(\ddot{\mathrm{Z}}_{1}+\ddot{\mathrm{Z}}_{2}\right)+\mathrm{K}_{\mathrm{zz} 1} \mathrm{Z}_{1}+\mathrm{K}_{\mathrm{zz} 2} \mathrm{Z}_{2}=0, \\
& \frac{2 \mathrm{I}_{\theta}}{\mathrm{L}^{2}}\left(\ddot{\mathrm{Z}}_{1}-\ddot{\mathrm{Z}}_{2}\right)+\mathrm{K}_{\mathrm{zz} 1} \mathrm{Z}_{1}-\mathrm{K}_{\mathrm{zz} 2} \mathrm{Z}_{2}=0, \\
& \mathrm{~m} \ddot{\mathrm{X}}+\left(\mathrm{C}_{\mathrm{xx} 1}+\mathrm{C}_{\mathrm{xx} 2}+2 \mathrm{~K}_{\mathrm{a}} \mathrm{v}_{0}\right) \dot{\mathrm{X}}=0 .
\end{aligned}
$$

In this case, the vehicle is stable at high speeds; this is similar to the two-degreeof-freedom vehicle. The natural frequency of vertical oscillations is the same as that in the two-degree-of-freedom system given in Eq. 25. The natural frequency of pitching oscillations is

$$
f_{p}=\frac{1}{2 \pi}\left(\frac{L^{2} m g}{4 I_{\theta} z_{0}}\right)^{0.5}
$$

For a square vehicle with length $\mathrm{L}$ and height $\mathrm{h}$, the natural frequency of pitching oscillations is

$$
f_{p}=\frac{1}{2 \pi}\left(\frac{g}{z_{0}}\right)^{0.5}\left(\frac{3}{1+\frac{h_{2}}{L^{2}}}\right)^{0.5}
$$

The natural frequency of pitching oscillations is larger than vertical oscillations. For a long vehicle $(h<L), f_{p}$ is equal to about $1.7 f_{v}$. For a square vehicle, $f_{p}=1.4$ $f_{v}$. At high speeds, heaving and pitching oscillations are stable for the magnetic levitation described by Eq. 15. In the forward direction, the result is the same as that for the two-degree-of-freedom vehicle. 


\subsection{Six-Degree-of-Freedom Vehicle}

For the six-degree-of-freedom vehicle shown in Fig. 1, stability can be studied from Eqs. 11 or 12 . Once the coefficients of magnetic forces $m_{i j}, c_{i j}$, and $k_{i j}$ are known, Eqs. 11 or 12 can be evaluated for $Q=0$. Let the displacement of a particular component be

$$
u_{j}(t)=a_{j} \exp (\lambda+i \omega) t .
$$

Substituting Eq. 36 into Eq. 12 with $Q=0$ yields

$$
\left\{(\lambda+i \omega)^{2}[M]+(\lambda+i \omega)[C]+[K]\right\}\{A\}=\{0\}
$$

The values of $\lambda$ and $\omega$ can be calculated based on Eq. 37 by setting the determinant of the coefficient matrix equal to zero.

Vehicle stability is determined by $\lambda$, which is a function of $\mathbf{v}$. If $\lambda<0$, vehicle motion is damped; if $\lambda>0$, vehicle displacement increases with time until nonlinear effects become important.

To solve this problem, all motion-dependent magnetic-force coefficients must be known. At this time, it appears that limited analytical, numerical, or experimental data are available. For any future maglev systems, it will be necessary to investigate the characteristics of motion-dependent magnetic forces to avoid dynamic instabilities.

\subsection{Vehicle on Double L-Shaped Aluminum Sheet Guideway}

Figure 9 shows a cross section of a vehicle on a double L-shaped aluminum sheet guideway. Assume that the vehicle travels at a constant velocity along $x$ direction. Two permanent magnets are attached to the bottom of vehicle and provide lift and guidance force $F_{L_{1}}, F_{L_{2}}, F_{G_{1}}$, and $F_{G_{2}}$ (see Fig. 9). Assume at the initial state that $h_{1}=h_{2}=h_{0}$ and $g_{1}=g_{2}=g_{0}$; thus, the vehicle and guideway geometries can be expressed as follows:

$$
\begin{aligned}
& \mathrm{L}_{1}=\mathrm{L}_{2}=\mathrm{S}=76.2(\mathrm{~mm}) \\
& \mathrm{W}=152.4+\mathrm{S}-2 \mathrm{~g}_{0}(\mathrm{~mm}) \\
& \mathrm{H}=0.9 \mathrm{~W}(\mathrm{~mm})
\end{aligned}
$$




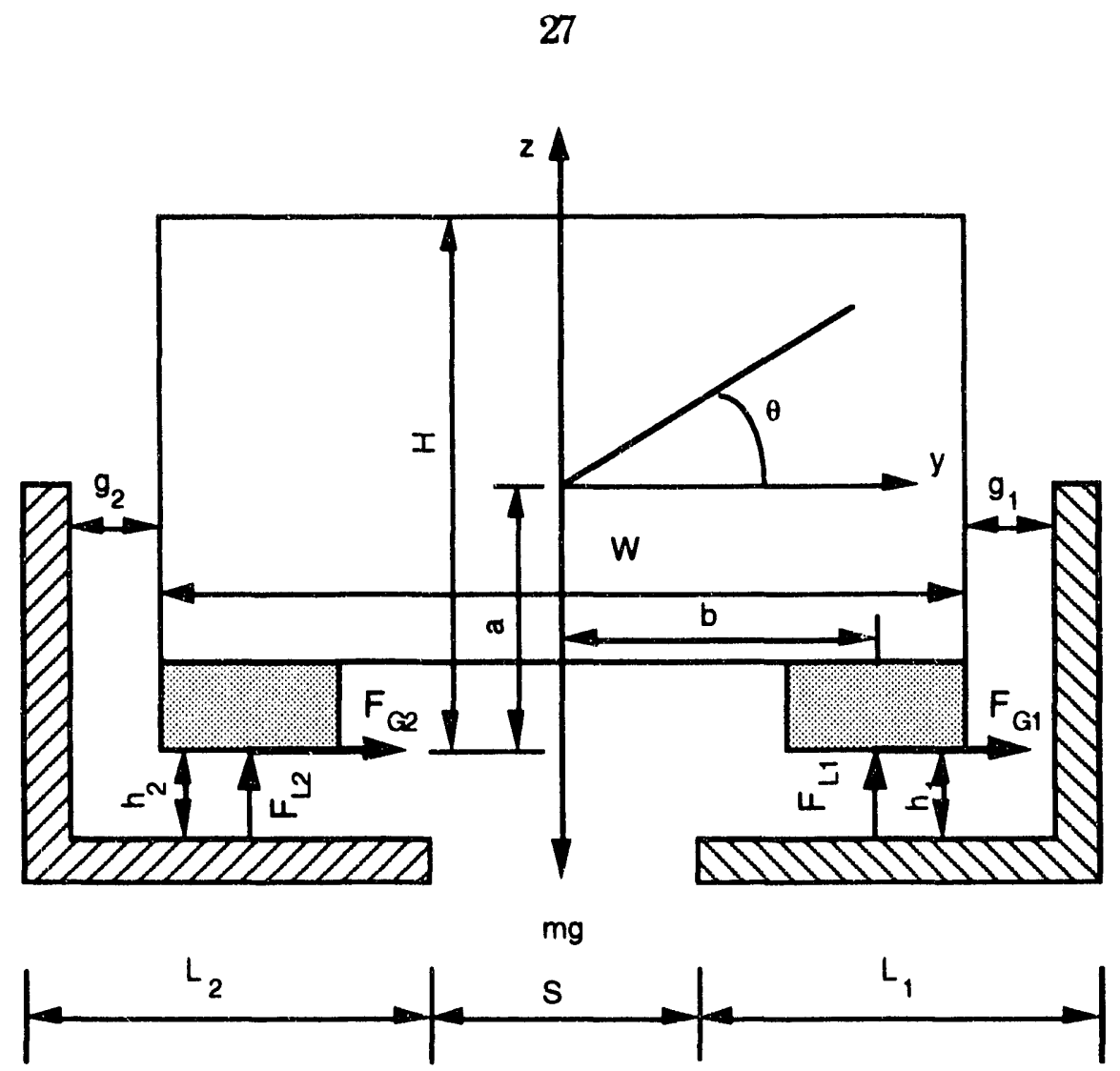

Fig. 9. Maglev system with a vehicle operating on double Lshaped aluminum sheet guideway

$$
\begin{aligned}
& \mathrm{a}=0.5 \mathrm{H}(\mathrm{mm}) \\
& \mathrm{b}=0.5(\mathrm{~W}-25.4)(\mathrm{mm})
\end{aligned}
$$

Equations of motion for this three-degree-of-freedom maglev system can be written as

$$
\begin{aligned}
& m \ddot{z}+C \dot{z}=F_{L_{1}}+F_{L_{2}}-m g \\
& I \ddot{\theta}+E \dot{\theta}=\left(F_{G_{1}}+F_{G_{2}}\right) a+\left(F_{G_{1}}+F_{G_{2}}\right) b \\
& m \ddot{y}+D \dot{y}=F_{G_{1}}+F_{G_{2}},
\end{aligned}
$$

where $\mathrm{m}$ is the mass of the vehicle, $\mathrm{C}$ and $\mathrm{D}$ are damping ratios; $\mathrm{I}$ is the moment of inertia about the center of mass inertia moment of the vehicle [I = $\left.(\mathrm{m} / 12)\left(\mathrm{H}^{2}+\mathrm{W}^{2}\right)\right] . \mathrm{F}_{\mathrm{L}_{1}}, \mathrm{~F}_{\mathrm{L}_{2}}, \mathrm{~F}_{\mathrm{G}_{1}}$, and $\mathrm{F}_{\mathrm{G}_{2}}$ are lift and guidance forces and are functions of $y$ and $z$. At the equilibrium position, they are $\mathrm{F}_{\mathrm{L}_{10}}\left(\mathrm{y}_{0}, \mathrm{z}_{0}\right), \mathrm{F}_{\mathrm{L}_{20}}\left(\mathrm{y}_{0}, \mathrm{z}_{0}\right)$, $\mathrm{F}_{\mathrm{G}_{10}}\left(\mathrm{y}_{0}, \mathrm{z}_{0}\right)$, and $\mathrm{F}_{\mathrm{G}_{20}}\left(\mathrm{y}_{0}, \mathrm{z}_{0}\right)$. Apply them to Eqs. 38: 


$$
\begin{aligned}
& F_{L_{10}}=F_{L_{20}} \\
& F_{L_{10}}+F_{L_{20}}=m g \\
& F_{G_{10}}=-F_{G_{20}}
\end{aligned}
$$

Therefore

$$
\mathrm{m}=\frac{\mathrm{F}_{\mathrm{L}_{10}}+\mathrm{F}_{\mathrm{L}_{20}}}{\mathrm{~g}}=\frac{2 \mathrm{~F}_{\mathrm{L}}\left(\mathrm{h}_{0}\right)}{\mathrm{g}} .
$$

Let

$$
\left.\begin{array}{l}
\mathrm{z}=\frac{1}{2}\left(\mathrm{u}_{1}+\mathrm{u}_{2}\right) \\
\mathrm{y}=\mathrm{u}_{3} \\
\theta=\left(\mathrm{u}_{1}-\mathrm{u}_{2}\right) / 2 \mathrm{~b}
\end{array}\right\},
$$

where $u_{1}, u_{2}$, and $u_{3}$ are shown in Fig. 10. Equations 38 can be rewritten as

$$
\begin{aligned}
& m\left(\ddot{u}_{1}+\ddot{u}_{2}\right)+c\left(\dot{u}_{1}-\dot{u}_{2}\right)=2\left(F_{L_{1}}+F_{L_{2}}-m g\right) \\
& \frac{I}{b}\left(\ddot{u}_{1}-\ddot{u}_{2}\right)+\frac{E}{b}\left(\dot{u}_{1}-\dot{u}_{2}\right)=2 a\left(F_{G_{1}}+F_{G_{2}}\right)+2 b\left(F_{G_{1}}-F_{G_{2}}\right) \\
& m \ddot{u}_{3}+D \dot{u}_{3}=F_{G_{1}}+F_{G_{2}} .
\end{aligned}
$$

Note the reduced dependence of the forces on the new displacements of Eq. 41:

$$
\begin{aligned}
& F_{L_{1}}=F_{L_{1}}\left(u_{1}, u_{3}\right) \\
& F_{L_{2}}=F_{L_{2}}\left(u_{2}, u_{3}\right) \\
& F_{G_{1}}=F_{G_{1}}\left(u_{1}, u_{3}\right) \\
& F_{G_{2}}=F_{G_{2}}\left(u_{2}, u_{3}\right) .
\end{aligned}
$$




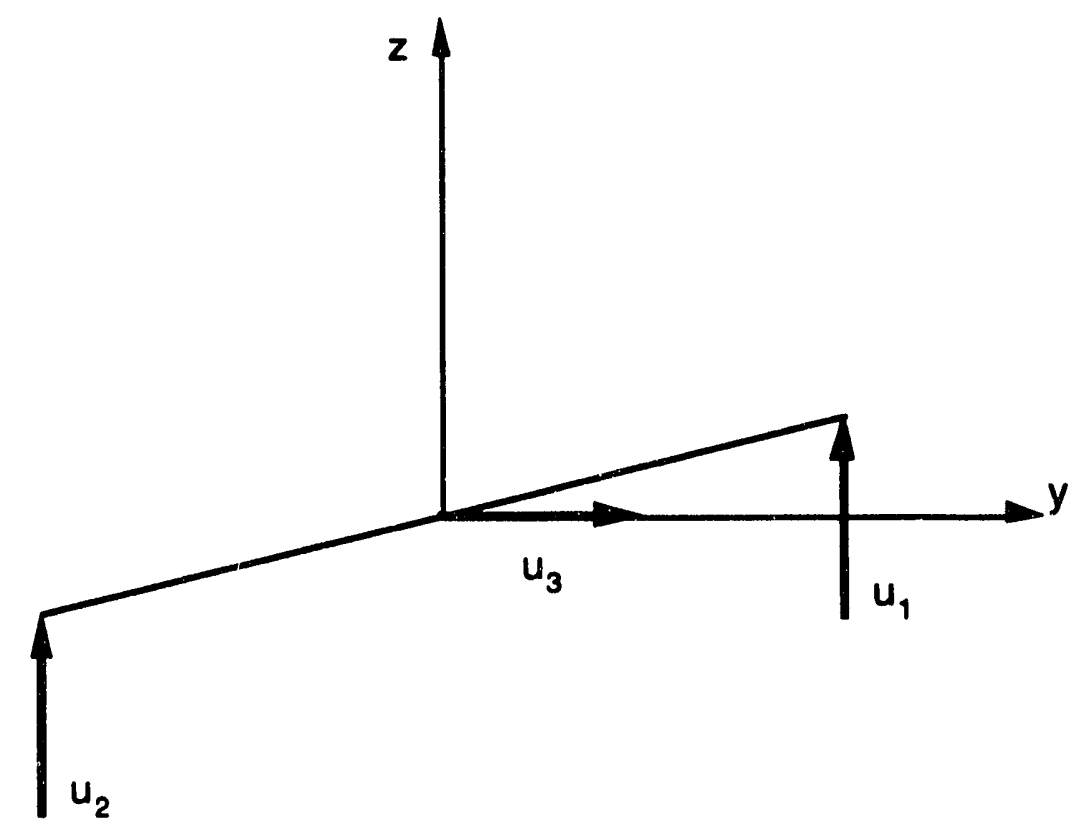

Fig. 10. Displacement components of three-degree-offreedom vehicle

Let

$$
u_{i}=u_{i o}+v_{i} \quad i=1,2
$$

The linear approximation of lift and guidance forces can be expressed as

$$
\begin{aligned}
& \mathrm{F}_{\mathrm{L}_{1}}=\mathrm{F}_{\mathrm{L}_{10}}+\frac{\partial \mathrm{F}_{\mathrm{L}_{1}}}{\partial \mathrm{v}_{1}} \mathrm{v}_{1}+\frac{\partial \mathrm{F}_{\mathrm{L} 1}}{\partial \mathrm{v}_{3}} \mathrm{v}_{3} \\
& \mathrm{~F}_{\mathrm{L}_{2}}=\mathrm{F}_{\mathrm{L}_{20}}+\frac{\partial \mathrm{F}_{\mathrm{L}_{2}}}{\partial \mathrm{v}_{2}} \mathrm{v}_{2}+\frac{\partial \mathrm{F}_{\mathrm{L} 2}}{\partial \mathrm{v}_{3}} \mathrm{v}_{3} \\
& \mathrm{~F}_{\mathrm{G}_{1}}=\mathrm{F}_{\mathrm{G}_{10}}+\frac{\partial \mathrm{F}_{\mathrm{G}_{1}}}{\partial \mathrm{v}_{1}} \mathrm{v}_{1}+\frac{\partial \mathrm{F}_{\mathrm{G} 1}}{\partial \mathrm{v}_{3}} \mathrm{v}_{3} \\
& \mathrm{~F}_{\mathrm{G}_{2}}=\mathrm{F}_{\mathrm{G}_{20}}+\frac{\partial \mathrm{F}_{\mathrm{G}_{2}}}{\partial \mathrm{v}_{2}} \mathrm{v}_{2}+\frac{\partial \mathrm{F}_{\mathrm{G} 2}}{\partial \mathrm{v}_{3}} \mathrm{v}_{3}
\end{aligned}
$$

Using Eqs. 39 and 45, we can rewrite Eq. 42 as 


$$
\begin{aligned}
\ddot{\mathrm{v}}_{1}+\ddot{\mathrm{v}}_{2}+\frac{\mathrm{C}}{\mathrm{m}} \dot{\mathrm{v}}_{1}+\frac{\mathrm{C}}{\mathrm{m}} \dot{\mathrm{v}}_{2}-\frac{2}{\mathrm{~m}} \frac{\partial \mathrm{F}_{\mathrm{L}_{1}}}{\partial \mathrm{v}_{1}} \mathrm{v}_{1}-\frac{2}{\mathrm{~m}} \frac{\partial \mathrm{F}_{\mathrm{L}_{2}}}{\partial \mathrm{v}_{2}} \mathrm{v}_{2}-\frac{1}{\mathrm{~m}}\left(\frac{\partial \mathrm{F}_{\mathrm{G}_{1}}}{\partial \mathrm{v}_{3}}+\frac{\partial \mathrm{F}_{\mathrm{G}_{2}}}{\partial \mathrm{v}_{3}}\right) \mathrm{v}_{3}=0 \\
-\ddot{\mathrm{v}}_{1}+\ddot{\mathrm{v}}_{2}-\frac{\mathrm{E}}{\mathrm{I}} \dot{\mathrm{v}}_{1}+\frac{\mathrm{E}}{\mathrm{I}} \dot{\mathrm{v}}_{2}+\left(\frac{2 \mathrm{cb}}{\mathrm{I}} \frac{\partial \mathrm{F}_{\mathrm{L}_{1}}}{\partial \mathrm{v}_{1}}+\frac{2 \mathrm{~b}^{2}}{\mathrm{I}} \frac{\partial \mathrm{F}_{\mathrm{G}_{1}}}{\partial \mathrm{v}_{1}}\right) \mathrm{v}_{1} \\
+\left(\frac{2 \mathrm{ab}}{\mathrm{I}} \frac{\partial \mathrm{F}_{\mathrm{L}_{2}}}{\partial \mathrm{v}_{2}}+\frac{2 \mathrm{~b}^{2}}{\mathrm{I}} \frac{\partial \mathrm{F}_{\mathrm{G}_{2}}}{\partial \mathrm{v}_{2}}\right) \mathrm{v}_{2} \\
+\left[\frac{2 \mathrm{ab}}{\mathrm{I}}\left(\frac{\partial \mathrm{F}_{\mathrm{L}_{1}}}{\partial \mathrm{v}_{3}}+\frac{\partial \mathrm{F}_{\mathrm{L}_{2}}}{\partial \mathrm{v}_{3}}\right)+\frac{2 \mathrm{~b}^{2}}{\mathrm{I}} \cdot\left(\frac{\partial \mathrm{F}_{\mathrm{G}_{1}}}{\partial \mathrm{v}_{3}}+\frac{\partial \mathrm{F}_{\mathrm{G}_{2}}}{\partial \mathrm{v}_{3}}\right)\right] \mathrm{v}_{3}=0 \\
\ddot{\mathrm{v}}_{3}+\frac{\mathrm{D}}{\mathrm{m}} \dot{\mathrm{v}}_{3}-\frac{1}{\mathrm{~m}} \frac{\partial \mathrm{F}_{\mathrm{L}_{1}}}{\partial \mathrm{v}_{1}} \mathrm{v}_{1}-\frac{1}{\mathrm{~m}} \frac{\partial \mathrm{F}_{\mathrm{L}_{2}}}{\partial \mathrm{v}_{2}} \mathrm{v}_{2}-\frac{1}{\mathrm{~m}}\left(\frac{\partial \mathrm{F}_{\mathrm{L}_{1}}}{\partial \mathrm{v}_{3}}+\frac{\partial \mathrm{F}_{\mathrm{L}_{2}}}{\partial \mathrm{v}_{3}}\right) \mathrm{v}_{3}=0
\end{aligned}
$$

or

$$
[\mathrm{M}]\{\ddot{\mathrm{v}}\}+[\mathrm{C}]\{\dot{\mathrm{v}}\}+[\mathrm{K}]\{\mathrm{v}\}=0
$$

where

$$
\mathrm{M}=\left[\begin{array}{ccc}
1 & 1 & 0 \\
-1 & 1 & 0 \\
0 & 0 & 1
\end{array}\right], \quad \mathrm{C}=\left[\begin{array}{ccc}
\mathrm{c}_{11} & \mathrm{c}_{22} & 0 \\
\mathrm{c}_{21} & \mathrm{c}_{22} & 0 \\
0 & 0 & \mathrm{c}_{23}
\end{array}\right], \quad \mathrm{K}=\left[\begin{array}{lll}
\mathrm{k}_{11} & \mathrm{k}_{12} & \mathbf{k}_{13} \\
\mathrm{k}_{21} & \mathrm{k}_{22} & \mathbf{k}_{23} \\
\mathrm{k}_{31} & \mathrm{k}_{32} & \mathbf{k}_{33}
\end{array}\right]
$$

and

$$
\begin{aligned}
& \mathrm{c}_{11}=\mathrm{c}_{12}=\frac{\mathrm{C}}{\mathrm{m}} \\
& \mathrm{c}_{21}=-\mathrm{c}_{22}=-\frac{\mathrm{E}}{\mathrm{I}} \\
& \mathrm{c}_{33}=\frac{\mathrm{D}}{\mathrm{m}} \\
& \mathrm{k}_{11}=-\frac{2}{\mathrm{~m}} \frac{\partial \mathrm{F}_{\mathrm{L}_{1}}}{\partial \mathrm{v}_{1}}
\end{aligned}
$$




$$
\begin{aligned}
& \mathrm{k}_{12}=-\frac{2}{\mathrm{~m}} \frac{\partial \mathrm{F}_{\mathrm{L}_{2}}}{\partial \mathrm{v}_{2}} \\
& \mathrm{k}_{13}=-\frac{1}{\mathrm{~m}}\left(\frac{\partial \mathrm{F}_{\mathrm{L}_{1}}}{\partial \mathrm{v}_{3}}+\frac{\partial \mathrm{F}_{\mathrm{L}_{2}}}{\partial \mathrm{v}_{3}}\right) \\
& \mathbf{k}_{21}=\frac{2 \mathrm{ab}}{\mathrm{I}} \frac{\partial \mathrm{F}_{\mathrm{G}_{1}}}{\partial \mathrm{v}_{1}}+\frac{2 \mathrm{~b}^{2}}{\mathrm{I}} \frac{\partial \mathrm{F}_{\mathrm{L}_{1}}}{\partial \mathrm{v}_{1}} \\
& \mathrm{k}_{22}=\frac{2 \mathrm{ab}}{\mathrm{I}} \frac{\partial \mathrm{F}_{\mathrm{G}_{2}}}{\partial \mathrm{v}_{2}}-\frac{2 \mathrm{~b}^{2}}{\mathrm{I}} \frac{\partial \mathrm{F}_{\mathrm{L}_{2}}}{\partial \mathrm{v}_{2}} \\
& \mathrm{k}_{23}=\frac{2 \mathrm{ab}}{\mathrm{I}}\left(\frac{\partial \mathrm{F}_{\mathrm{G}_{1}}}{\partial \mathrm{v}_{3}}+\frac{\partial \mathrm{F}_{\mathrm{G}_{2}}}{\partial \mathrm{v}_{3}}\right)+\frac{2 \mathrm{~b}^{2}}{\mathrm{I}}\left(\frac{\partial \mathrm{F}_{\mathrm{L}_{1}}}{\partial \mathrm{v}_{3}}+\frac{\partial \mathrm{F}_{\mathrm{L}_{2}}}{\partial \mathrm{v}_{3}}\right) \\
& \mathrm{k}_{31}=-\frac{1}{\mathrm{~m}} \frac{\partial \mathrm{F}_{\mathrm{G}_{1}}}{\partial \mathrm{v}_{1}} \\
& \mathrm{k}_{32}=-\frac{1}{\mathrm{~m}} \frac{\partial \mathrm{F}_{\mathrm{G}_{2}}}{\partial \mathrm{v}_{2}} \\
& \mathbf{k}_{33}=-\frac{1}{\mathrm{~m}}\left(\frac{\partial \mathrm{F}_{\mathrm{G}_{1}}}{\partial \mathrm{v}_{3}}+\frac{\partial \mathrm{F}_{\mathrm{G}_{2}}}{\partial \mathrm{v}_{3}}\right)
\end{aligned}
$$

where

$$
\begin{aligned}
\frac{\partial \mathrm{F}_{\mathrm{L}_{1}}}{\partial \mathrm{v}_{1}}=\mathrm{k}_{\ell \ell}(\mathrm{h}), & \frac{\partial \mathrm{F}_{\mathrm{G}_{1}}}{\partial \mathrm{v}_{1}}=-\mathbf{k}_{\mathrm{g} \ell}(\mathrm{h}), \\
\frac{\partial \mathrm{F}_{\mathrm{L}_{2}}}{\partial \mathrm{v}_{2}}=\mathrm{k}_{\ell \ell}(\mathrm{h}), & \frac{\partial \mathrm{F}_{\mathrm{G}_{2}}}{\partial \mathrm{v}_{2}}=\mathbf{k}_{\mathrm{g} \ell}(\mathrm{h}), \\
\frac{\partial \mathrm{F}_{\mathrm{L}_{1}}}{\partial \mathrm{v}_{3}}=\mathrm{k}_{\ell \mathrm{g}}(\mathrm{g}), & \frac{\partial \mathrm{F}_{\mathrm{G}_{1}}}{\partial \mathrm{v}_{3}}=\mathbf{k}_{\mathrm{gg}}(\mathrm{g}), \\
\frac{\partial \mathrm{F}_{\mathrm{L}_{2}}}{\partial \mathrm{v}_{3}}=\mathrm{k}_{\ell \mathrm{g}}(\mathrm{g}), & \frac{\partial \mathrm{F}_{\mathrm{G}_{2}}}{\partial \mathrm{v}_{3}}=\mathbf{k}_{\mathrm{gg}}(\mathrm{g}) .
\end{aligned}
$$


$\mathbf{k}_{\ell \ell}(\mathrm{h}), \mathbf{k}_{\ell \mathrm{g}}(\mathrm{g}), \mathbf{k}_{\mathrm{g} \ell}(\mathrm{h})$, and $\mathbf{k}_{\mathrm{gg}}(\mathrm{g})$ are motion-dependent magnetic-force coefficients (see Fig. 5).

If we assume that the damping effects can be neglected, the eigenvalues of Eq. 47 can be obtained from

$$
[\mathrm{K}]\{\mathrm{v}\}=\lambda[\mathrm{M}]\{\mathrm{v}\}
$$

where $\lambda=\omega_{\mathrm{R}}+\mathrm{i} \omega_{\mathrm{I}}$.

With magnetic forces and stiffnesses measured by the experiments (see Figs. 4 and 5), the eigenvalues and eigenvectors of a maglev vehicle on a double L-shaped guideway were calculated with the theoretical model developed in this section. Some very interesting results were obtained from those calculations.

Figure 11 shows that eigenvalues of vehicle motion versus levitation height vary when guidance gaps are fixed $\left(\mathrm{g}_{1}=\mathrm{g}_{2}=\mathrm{Y}^{*}=12.7 \mathrm{~mm}\right)$. The first mode $\omega_{1}$ shows an uncoupled heave motion; its irnaginary part of the eigenvalue is zero, while the second and third modes are coupled roll-sway motions. Within the range of height $h=19.0$ to $35 \mathrm{~mm}$, the imaginary parts of the eigenvalues appear not to be zero. This indicates that within this range, flutter does exist for these coupled roll-sway vibrations. Table 1 and Fig. 12 give eigenvectors and modal shapes of these three modes of vehicle motion, respectively. When the guidance gaps are fixed at $\mathrm{g}_{1}=\mathrm{g}_{2}=\mathrm{Y}^{*}=5 \mathrm{~mm}$, the same results are obtained, as shown in Fig. 13; there is a flutter for coupled roll-sway modes.

Table 1. Eigenvectors of vehicle motion $\left(Y^{*}=12.7 \mathrm{~mm}\right)$

\begin{tabular}{|c|c|c|c|c|c|c|c|c|c|}
\hline \multirow[b]{2}{*}{ Mode } & \multicolumn{3}{|c|}{$\mathrm{h}=15.0 \mathrm{~mm}$} & \multicolumn{3}{|c|}{$\mathrm{h}=25 \mathrm{~mm}$} & \multicolumn{3}{|c|}{$\mathrm{h}=37 \mathrm{~mm}$} \\
\hline & $\mathrm{v}_{1}$ & $\mathrm{v}_{2}$ & $v_{3}$ & $\mathrm{v}_{1}$ & $\mathrm{v}_{2}$ & $v_{3}$ & $\mathrm{v}_{1}$ & v2 & v3 \\
\hline $\begin{array}{l}\text { Uncoupled } \\
\text { heave mode } \\
\omega_{1}\end{array}$ & 1 & 1 & 0 & 1 & 1 & 0 & 1 & 1 & 0 \\
\hline $\begin{array}{l}\text { Coupled } \\
\text { roll-sway } \\
\text { mode } \omega_{2}\end{array}$ & 1 & -1 & -0.009 & 0.586 & -0.586 & -0.332 & -1 & 1 & -0.205 \\
\hline $\begin{array}{l}\text { Coupled } \\
\text { roll-sway } \\
\text { mode } \omega_{3}\end{array}$ & -0.545 & 0.545 & 1 & -0.810 & 0.810 & 0.060 & 1 & -1 & 0.448 \\
\hline
\end{tabular}



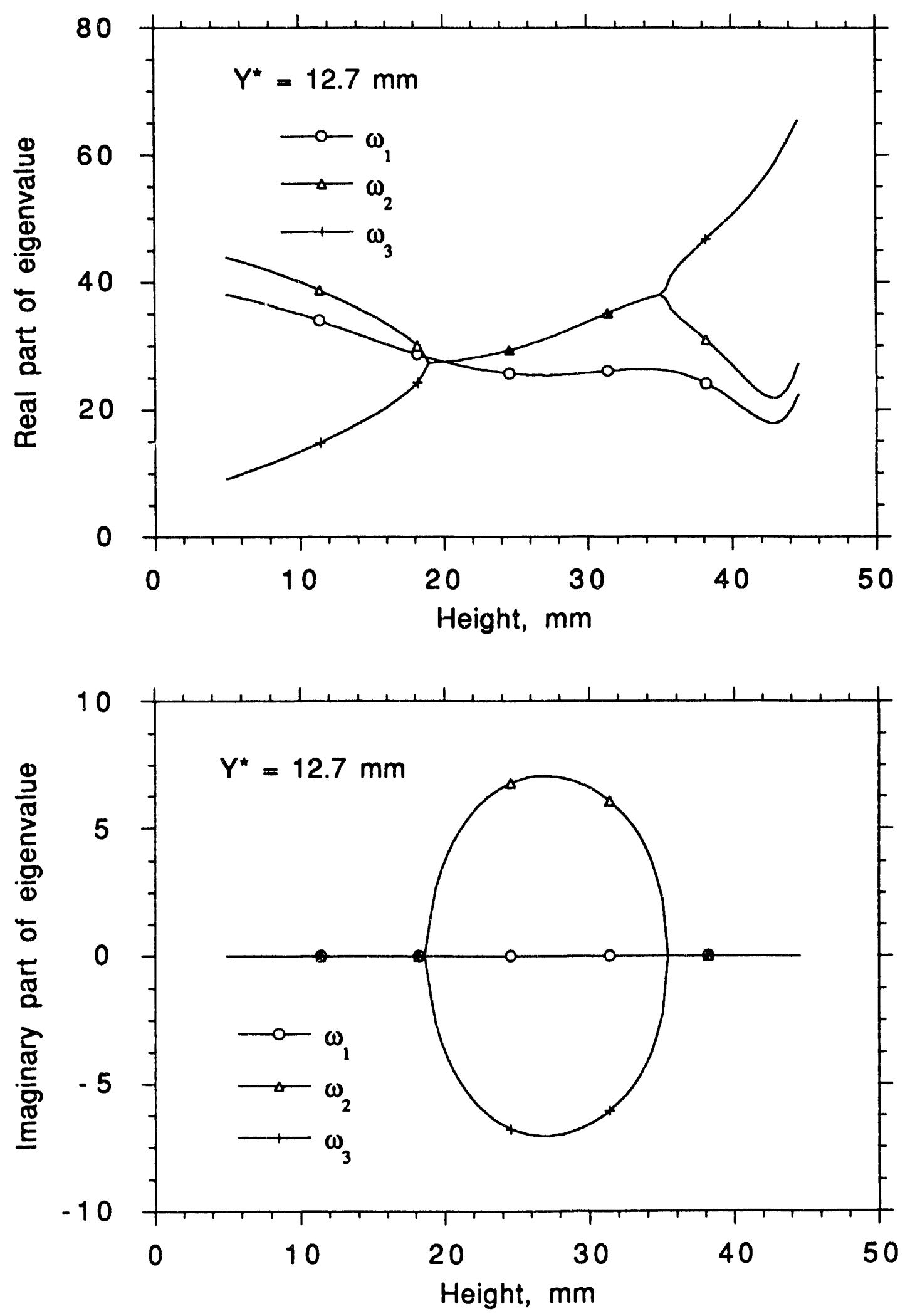

Fig. 11. Maglev-system eigenvalues vs. vehicle levitation height, with $Y^{*}=12.7 \mathrm{~mm}$ 

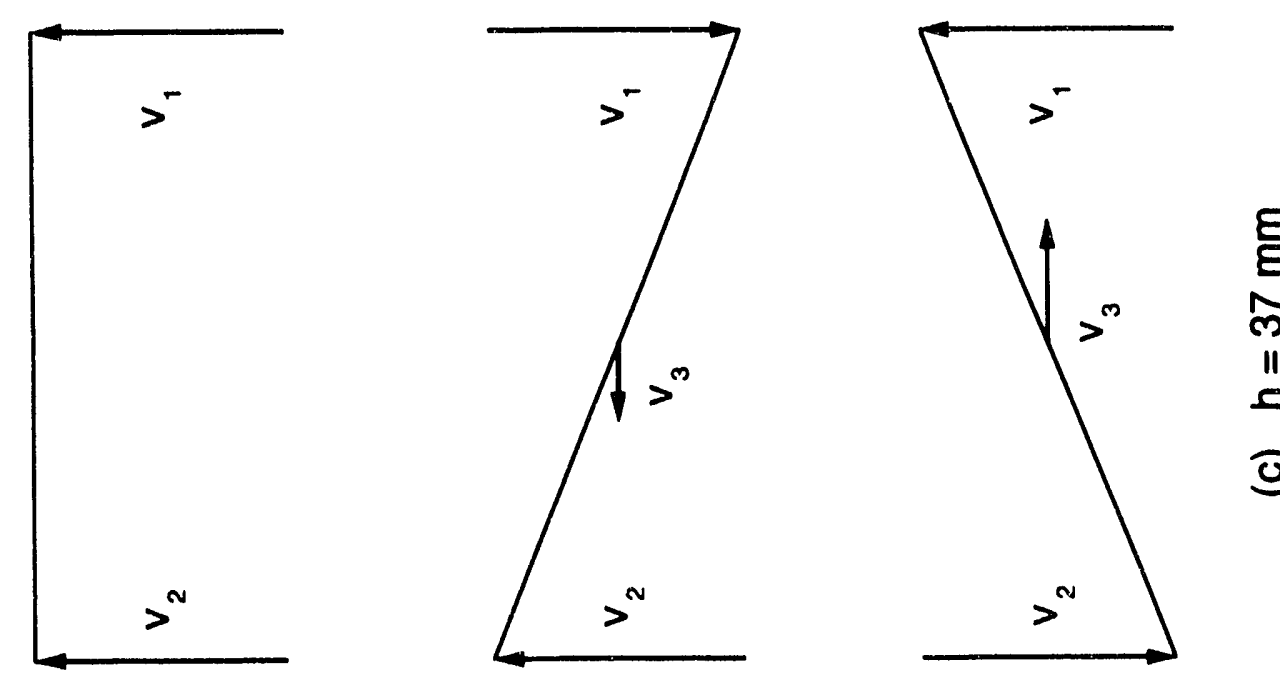

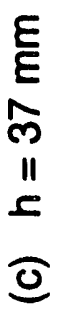

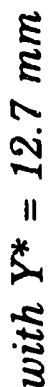
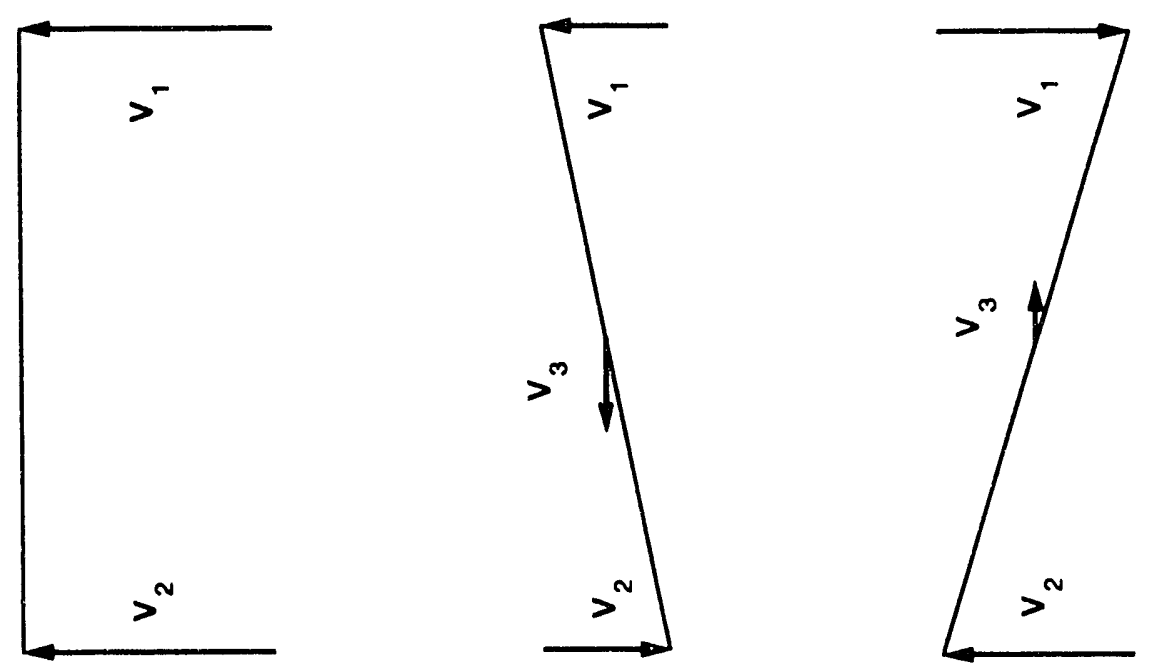

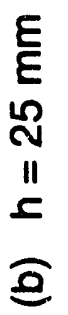
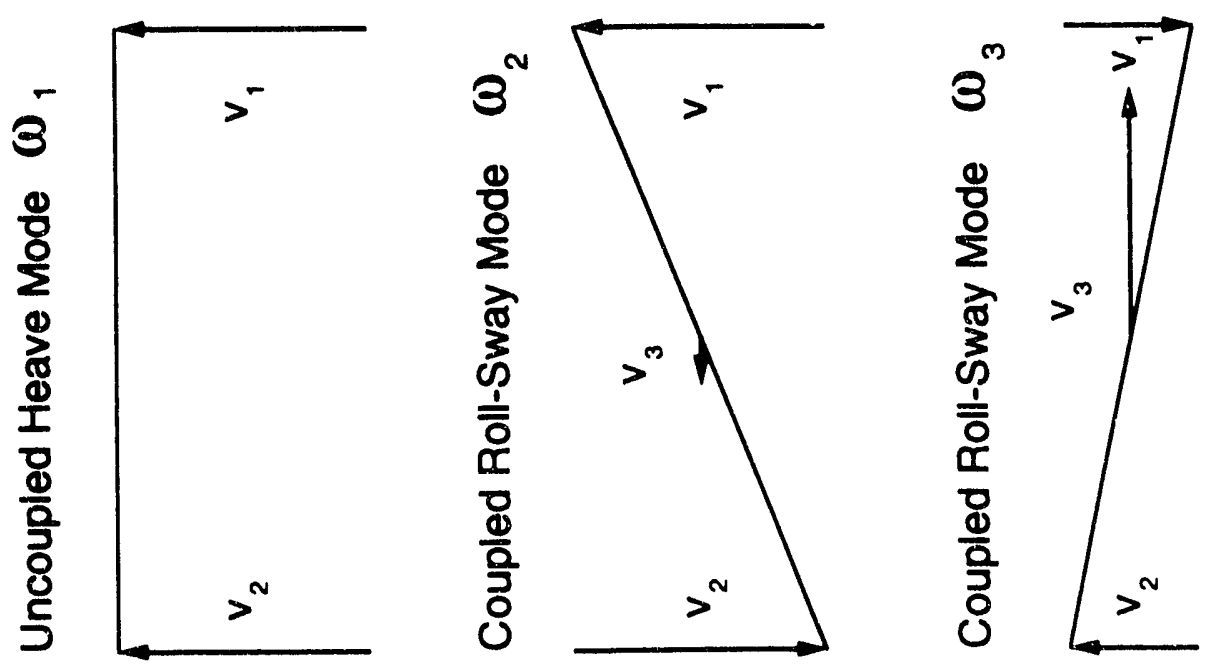

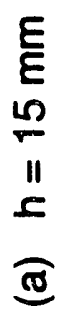



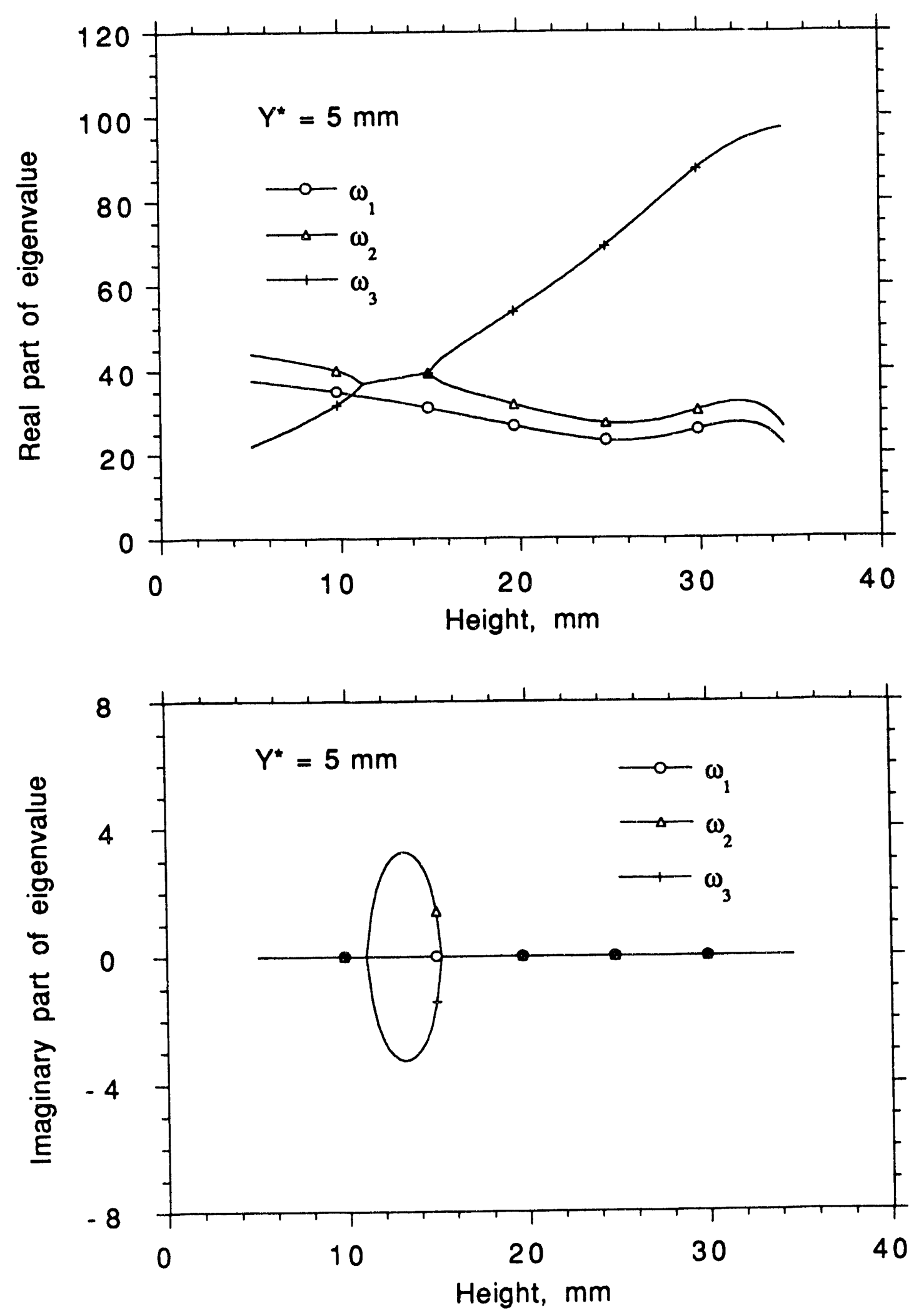

Fig. 13. Maglev-system eigenvalues vs. vehicle levitation height, with $Y^{*}=5 \mathrm{~mm}$ 
Figures 14 and 15 show eigenvalues of vehicle motion versus lateral location of vehicle when $\mathrm{g}_{1}=\mathrm{g}_{2}=\mathrm{g}_{0}=25 \mathrm{~mm}$ and levitation heights $\mathrm{h}=12.7 \mathrm{~mm}$ and $\mathrm{h}=$ $7 \mathrm{~mm}$, respectively. We notice that for the third mode, which presents the transversal motion of vehicle, the real part is zero and imaginary part is not zero within a certain region. This indicates that the divergence is subjected to the lateral motion of the vehicle, given those vehicle and guideway parameters. Figure 16 shows the real part of the third mode versus lateral location of vehicle when the parameter-equilibrium guidance gap varies as $\mathrm{g}_{1}=\mathrm{g}_{2}=\mathrm{g}_{0}=10 \mathrm{~mm}$, $15 \mathrm{~mm}, 20 \mathrm{~mm}$, and $25 \mathrm{~mm}$. We found that divergence appears only in the case of $\mathrm{g}_{0}=25 \mathrm{~mm}$.

We must point out that the measured and calculated data for motiondependent magnetic-forces and force coefficients are very limited and that damping effects were not considered in the above analysis. Even though divergence and flutter appear in the eigenvalue results, we still have difficulty in completely predicting the dynamic instability of this three-degree-of-freedom maglev vehicle model. Further research is needed in modeling to gain an understanding of dynamic instability in maglev systems.

\section{Closing Remarks}

- Motion-dependent magnetic forces are the key elements in modeling and understanding dynamic instabilities of maglev systems. At this time, it appears that very limited data are available for motiondependent magnetic forces. Efforts will be made to compile analytical results and experimental data for motion-dependent magnetic forces. When this work is completed, recommendations will be presented on research needs on magnetic forces. In addition, specific methods to obtain motion-dependent magnetic forces will be described in detail.

- Various options can be used to stabilize a maglev system: passive electrodynamic primary suspension damping, active electrodynamic primary suspension damping, passive mechanical secondary suspension, and active mechanical secondary suspension. With a better understanding of vehicle stability characteristics, a better control law can be adopted to ensure a high level of ride comfort and safety. 

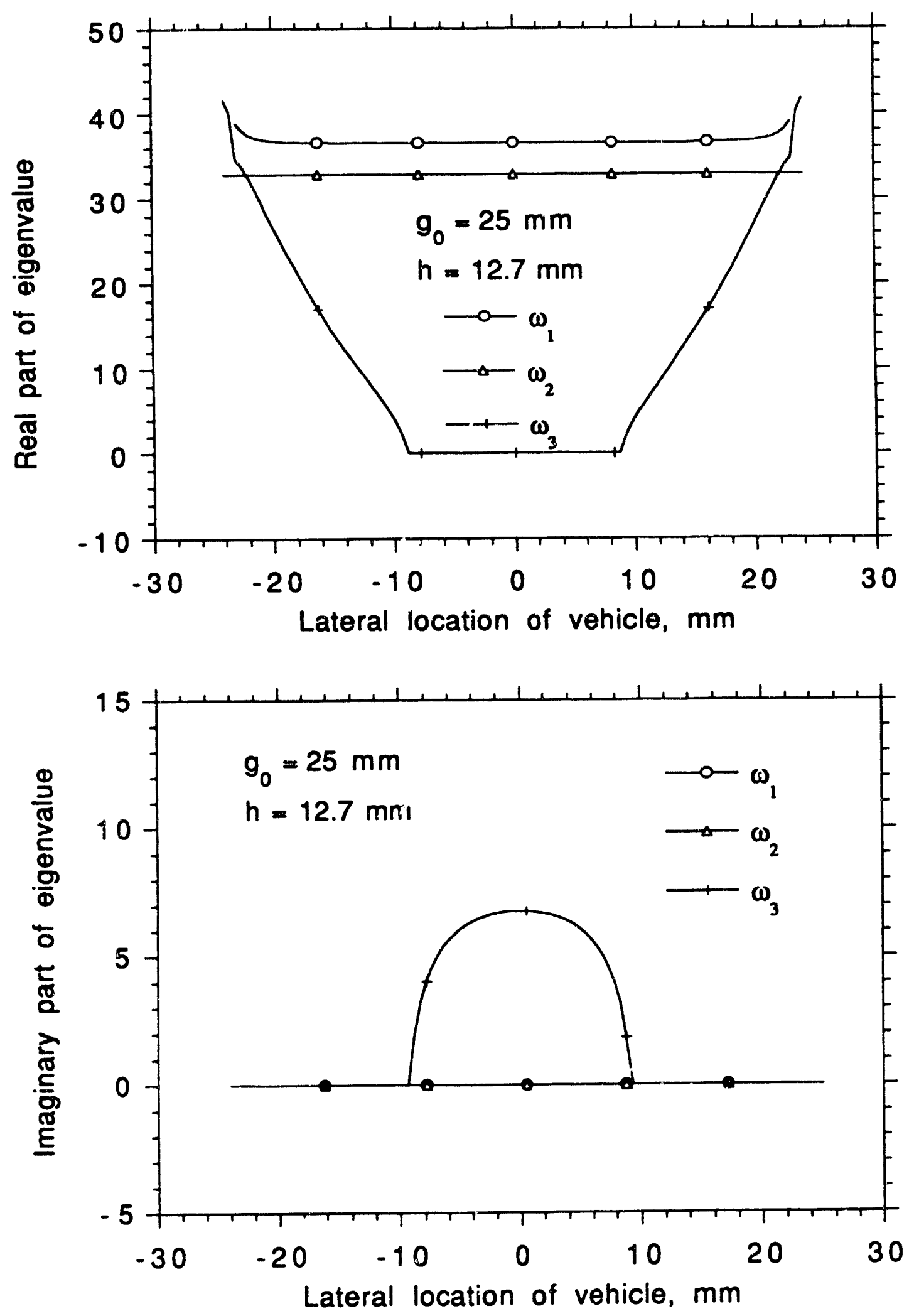

Fig. 14. Maglev-system eigenvalues vs. lateral location of vehicle, with $h=12.7 \mathrm{~mm}$ and $g_{0}=25 \mathrm{~mm}$ 

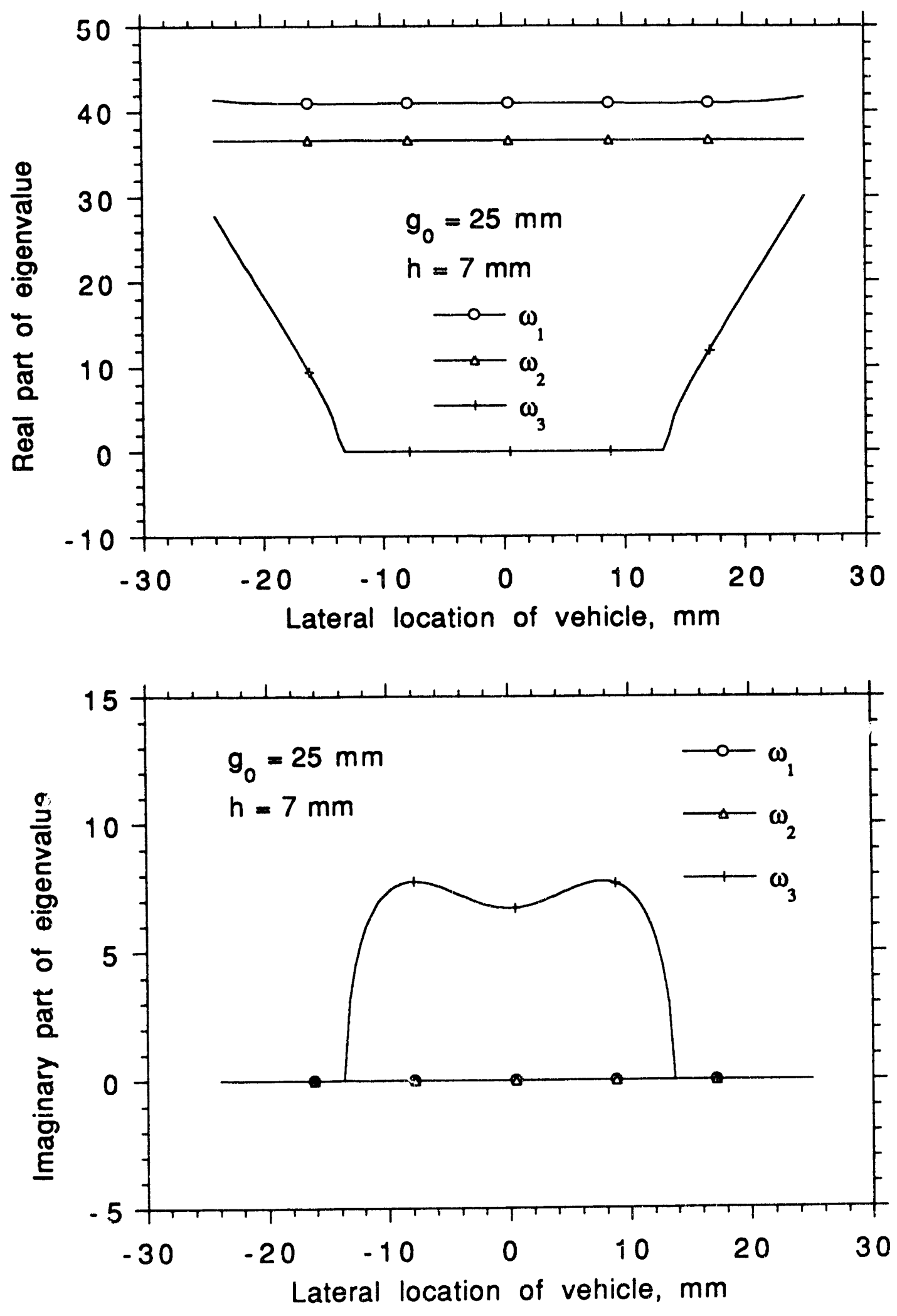

Fig. 15. Maglev-system eigenvalues vs. lateral location of vehicle, with $h=7 \mathrm{~mm}$ and $g_{0}=25 \mathrm{~mm}$ 


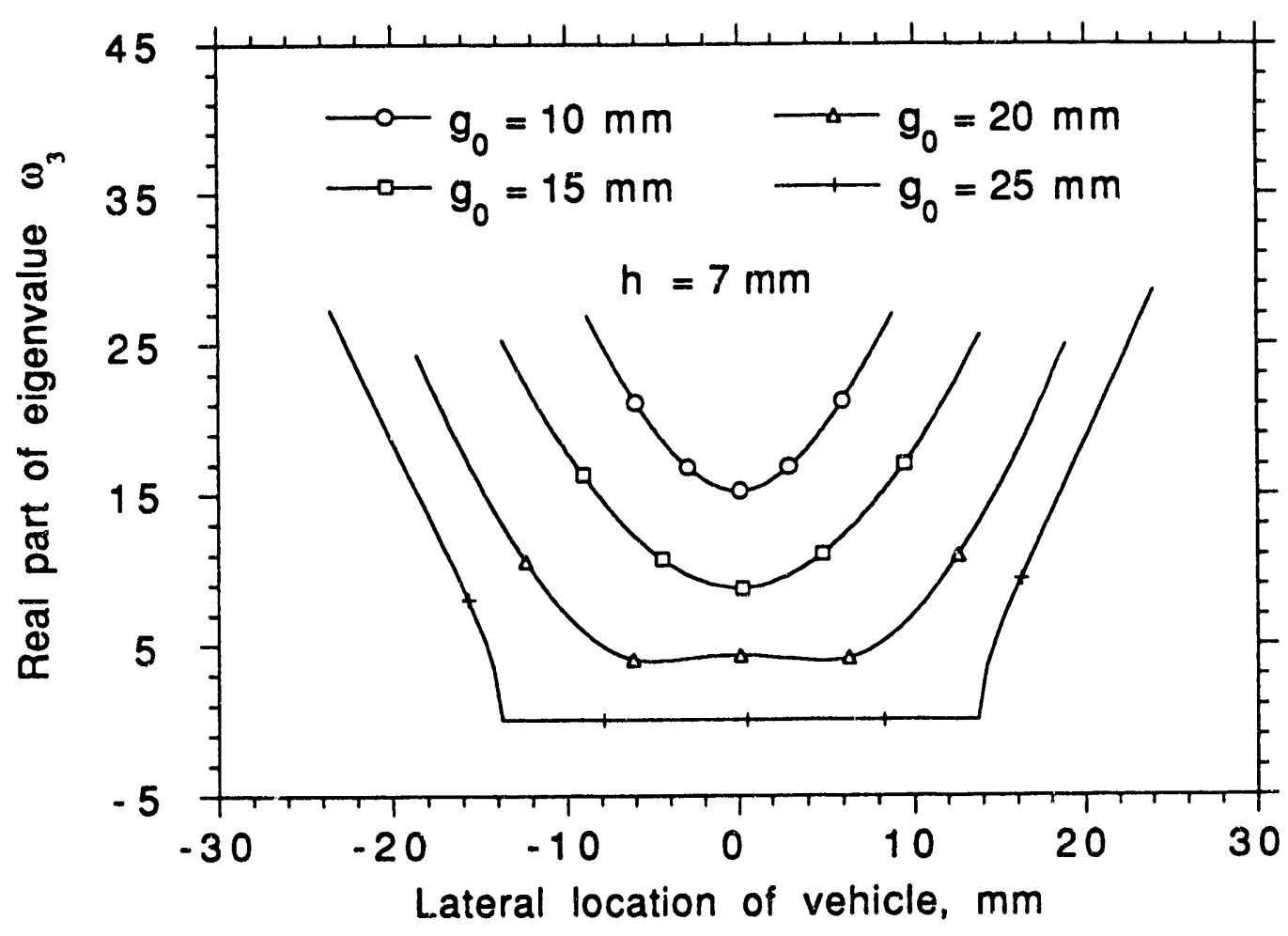

Fig. 16. Real part of maglev-system eigenvalues vs. lateral location of vehicle, with $h=7 \mathrm{~mm}$ and $g_{0}=10,15$, 20 , and $25 \mathrm{~mm}$

- Computer programs are needed to screen new system concepts, evaluate various designs, and predict vehicle response. It appears that the stability characteristics of maglev vehicles under different conditions have not been studied in detail in existing computer codes. When information on motion-dependent magnetic forces becomes available, the existing computer codes can be significantly improved.

- Instabilities of maglev-system models have been observed at Argonne and other organizations. An integrated experimental/analytical study of stability characteristics is an important aspect of maglev research.

\section{Acknowledgments}

This work was performed under the sponsorship of the U.S. Army Corps of Engineers and the Federal Railroad Administration through interagency agreements with the U.S. Department of Energy.

Additional thanks to S. Winkelman for performing tests on magnetic forces. 


\section{References}

Chen, S. S. (1987), Flow-Induced Vibration of Circular Cylindrical Structures, Hemisphere Publishing Co., New York.

Chu, D., and Moon, F. C. (1983), Dynamic Instabilities in Magnetically Levitated Models, J. Appl. Phys. 54(3), pp. 1619-1625.

Davis, L. C., and Wilkie, D. F. (1971), Analysis of Motion of Magnetic Levitation Systems: Implications, J. Appl. Phys. 42(12), pp. 4779-4793.

Moon, F. C. (1974), Laboratory Studies of Magnetic Levitation in the Thin Track Limit, IEEE Trans. on Magnetics, MAG-10, No. 3, pp. 439-442 (September 1974).

Moon, F. C. (1975), "Vibration Problems in Magnetic Levitation and Propulsion," Transport Without Wheels, ed. by E. R. Laithwaite, Elek Science, London, pp. 122-161.

Ohno, E., Iwamoto, M., and Yamada, T. (1973), Characteristic of Superconductive Magnetic Suspension and Propulsion for High-Speed Trains, Proc. IEEE 61(5), pp. 579-586.

Rhodes, R. G., and Mulhall, B. E. (1981), Magnetic Levitation for Rail Transport, Oxford University Press, New York.

Sinha, P. K. (1987), Electromagnetic Suspension, Dynamics and Control, Peter Peregrinus Ltd, London, United Kingdom.

Yabuno, H., Takabayashi, Y., Yoshizawa, M., and Tsujioka, Y. (1989), Bounding and Pitching Oscillations of a Magnetically Levitated Vehicle Caused by Guideway Roughness, Int. Conference Maglev 89, pp. 405-410. 
Distribution for ANL-92/21

\section{Internal}

Y. Cai (10)

S. S. Chen (10)

J. L. He

L. R. Johnson

C. A. Malefyt (2)

T. M. Mulcahy (5)

D. M. Rote (5)

R. A. Valentin
M. W. Wambsganss (3)

Z. Wang

R. W. Weeks

S. Zhu

ANL Patent Dept.

ANL Contract File

TIS Files (3)

\section{External}

DOE-OSTI for distribution per UC-330 (91)

ANL-TIS Libraries (2)

Manager, Chicago Operations Office, DOE

Director, Technology Management Div., DOE-CH

D. L. Bray, DOE-CH

A. L. Taboas, DOE-CH

Materials and Components Technology Division Review Committee:

H. K. Birnbaum, University of Illinois at Urbana-Champaign, Urbana

R. C. Buchanan, University of Illinois at Urbana-Champaign, Urbana

M. S. Dresselhaus, Massachusetts Institute of Technology, Cambridge, MA

B. G. Jones, University of Illinois at Urbana-Champaign, Urbana

C.-Y. Li, Cornell University, Ithaca, NY

S.-N. Liu, Electric Power Research Institute, Palo Alto, CA

R. E. Smith, Engineering Applied Sciences, Inc., Trafford, PA

O. P. Manley, DOE, Washington, DC

J. S. Coleman, DOE, Washington, DC

D. Frederick, DOE, Washington, DC

F. C. Moon, Cornell University, Ithaca, NY 

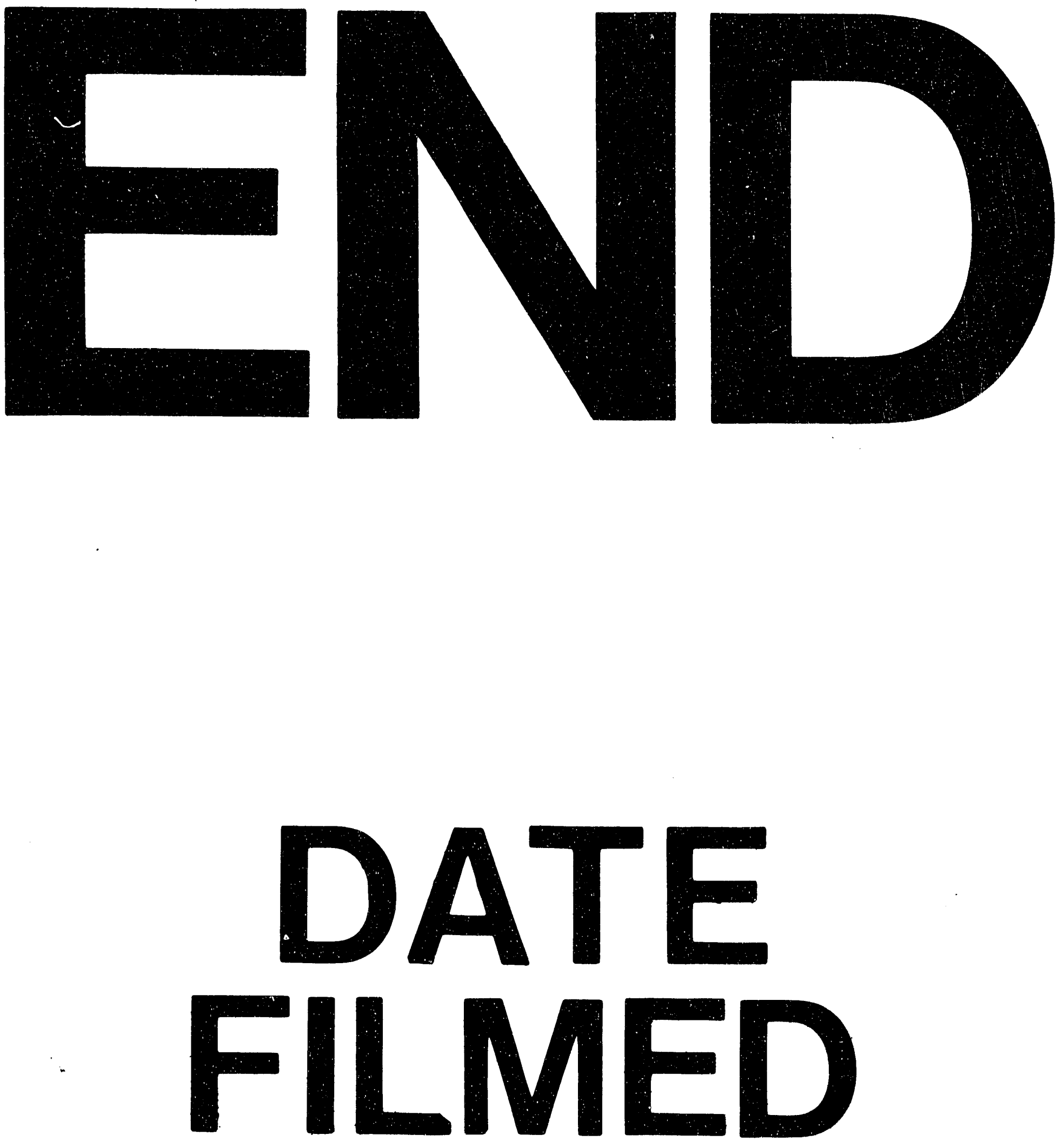

1

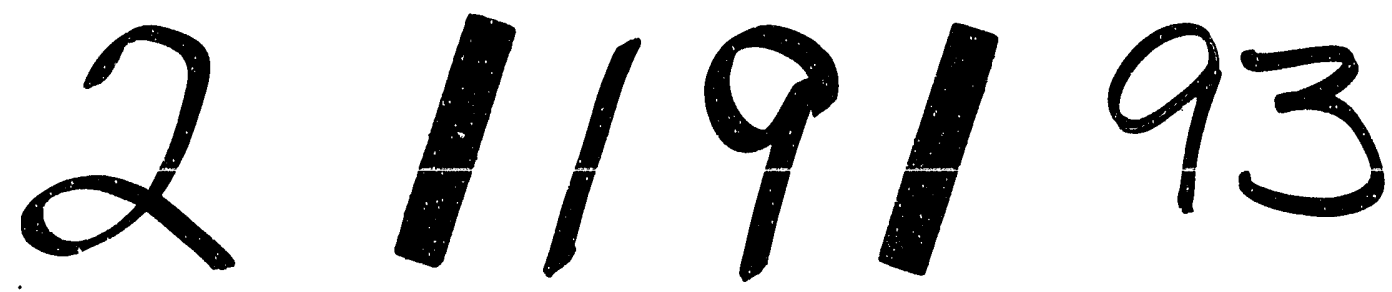


